Measuring Physicians' Response to Incentives:

Evidence on Hours Worked and Multitasking

BRUCE SHEARER

NIBENE HABIB SOMÉ BERNARD FORTIN 
2018s-19

\title{
Measuring Physicians' Response to Incentives: Evidence on Hours Worked and Multitasking
}

\author{
Bruce Shearer, Nibene Habib Somé, Bernard Fortin
}

Série Scientifique
Scientific Series

\author{
Montréal \\ Mai/May 2018
}

(C) 2018 Bruce Shearer, Nibene Habib Somé, Bernard Fortin. Tous droits réservés. All rights reserved. Reproduction partielle permise avec citation du document source, incluant la notice C. Short sections may be quoted without explicit permission, if full credit, including ${ }^{\circ}$ notice, is given to the source.

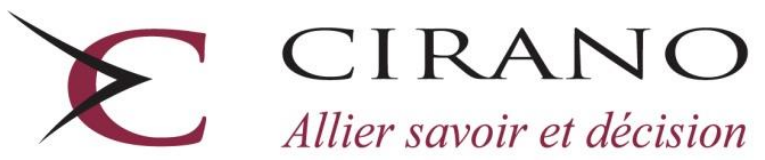

Centre interuniversitaire de recherche en analyse des organisations 


\section{CIRANO}

Le CIRANO est un organisme sans but lucratif constitué en vertu de la Loi des compagnies du Québec. Le financement de son infrastructure et de ses activités de recherche provient des cotisations de ses organisations-membres, d'une subvention d'infrastructure du gouvernement du Québec, de même que des subventions et mandats obtenus par ses équipes de recherche.

CIRANO is a private non-profit organization incorporated under the Quebec Companies Act. Its infrastructure and research activities are funded through fees paid by member organizations, an infrastructure grant from the government of Quebec, and grants and research mandates obtained by its research teams.

\section{Les partenaires du CIRANO}

\section{Partenaires corporatifs}

Autorité des marchés financiers

Banque de développement du Canada

Banque du Canada

Banque Laurentienne

Banque Nationale du Canada

Bell Canada

BMO Groupe financier

Caisse de dépôt et placement du Québec

Énergir

Hydro-Québec

Innovation, Sciences et Développement économique Canada

Intact Assurance

Investissements PSP

Ministère de l'Économie, de la Science et de l'Innovation

Ministère des Finances du Québec

Mouvement Desjardins

Power Corporation du Canada

Rio Tinto

Ville de Montréal

\section{Partenaires universitaires}

École de technologie supérieure

HEC Montréal

Institut national de la recherche scientifique

Polytechnique Montréal

Université Concordia

Université de Montréal

Université de Sherbrooke

Université du Québec

Université du Québec à Montréal

Université Laval

Université McGill

Le CIRANO collabore avec de nombreux centres et chaires de recherche universitaires dont on peut consulter la liste sur son site web.

Les cahiers de la série scientifique (CS) visent à rendre accessibles des résultats de recherche effectuée au CIRANO afin de susciter échanges et commentaires. Ces cahiers sont écrits dans le style des publications scientifiques. Les idées et les opinions émises sont sous l'unique responsabilité des auteurs et ne représentent pas nécessairement les positions du CIRANO ou de ses partenaires.

This paper presents research carried out at CIRANO and aims at encouraging discussion and comment. The observations and viewpoints expressed are the sole responsibility of the authors. They do not necessarily represent positions of CIRANO or its partners. 


\title{
Measuring Physicians' Response to Incentives: Evidence on Hours Worked and Multitasking
}

\author{
Bruce Shearer ${ }^{*}$, Nibene Habib Somé ${ }^{*}$, Bernard Fortin *
}

\begin{abstract}
Résumé/Abstract
We measure the response of physicians to monetary incentives using matched administrative and time-use data on specialists from Québec (Canada). These physicians were paid fee-forservice contracts and supplied a number of different services. Our sample covers a period during which the Québec government changed the prices paid for clinical services. We apply these data to a multitasking model of physician labour supply, measuring two distinct responses. The first is the labour-supply response of physicians to broad-based fee increases. The second is the response to changes in the relative prices of individual services. Our results confirm that physicians respond to incentives in predictable ways. The own-price substitution effects of a relative price change are both economically and statistically significant. Income effects are present, but are overridden when prices are increased for individual services. They are more prominent in the presence of broad-based fee increases. In such cases, the income effect empirically dominates the substitution effet, which leads physicians to reduce their supply of clinical services.
\end{abstract}

Mots clés/Keywords: Physician Labour Supply; Multitasking; Incentive Pay

Codes JEL/JEL Codes: I10; J22; J33; J44

\footnotetext{
* Contact Author: Département d'économique, Université Laval, CRREP, CIRANO and IZA. Bruce.Shearer@Ecn.Ulaval.Ca.

$\dagger$ Department of Epidemiology and Biostatistics, Schulich School of Medicine, University of Western Ontario. Nsome@UWO.Ca.

* Département d'économique, Université Laval, CRREP, CIRANO and IZA.

Bernard.Fortin@Ecn.Ulaval.Ca.
} 


\section{Introduction}

Measuring how physicians react to incentives has important implications for health-care policies in the face of changing demand. At least two basic issues are at stake for a given number of physicians. First, beginning with Feldstein (1970), Rizzo and Blumenthal (1994) and Baltagi, Bratberg, and Holmas (2005), much attention has been paid to characterizing the shape of physician labour-supply curves - in particular whether or not they are backward bending at high levels of the wage rate - and the resulting implications for policies aimed at increasing the total supply of services (e.g., Sloan, 1975). A second concern is whether a change in the relative fees paid for a particular service leads physicians to reallocate their hours of work to increase the supply of that service. For instance, an ageing population is likely to increase the demand for certain services: cardiovascular treatments, cataract surgeries, and hip replacements are examples. Since training more physicians takes time, monetary incentives can provide the government with a policy tool to meet demand changes in the short run.

Relatively little is known about how physicians react to relative fee changes, particularly with respect to the relative sizes of income and substitution effects. Some studies have looked at the supply of isolated services in response to variation in remuneration rates. For example, Allin, Baker, Isabelle, and Stabile (2015) found that the propensity to deliver babies by Cesarean section across Canadian provinces was sensitive to the relative price paid to physicians for completing that service ${ }^{1}$ The natural-experiment empirical approach exploited by the authors provides robust evidence of the total reaction to incentives, but does not distinguish income from substitution effects (see Blundell and Macurdy, 1999). Other studies have relied on geographically-aggregated service data, often with mixed results. Hurley and Labelle (1995) considered how changes in the relative fee paid for given services affected the completion rates of those services in Canadian provinces. They found little consistency in results across services, either in terms of the statistical significance of the relative fee as a determinant of the utilization rate, or in the direction of the effect.

This paper develops and estimates an economic model which fully characterizes physicians' response to incentives. We analyse physician choices over the total hours they spend seeing patients and the manner in which those hours are allocated to different ser-

${ }^{1}$ Gruber and Owings (1996) found that the propensity to complete Cesarean sections across American states was inversely related to negative income shocks such as a decline in fertility rates, consistent with physician-induced demand (Evans, 1974). 
vices, which we refer to as multitasking $\left.\right|^{2}$ We also specify the complete production process that transforms hours devoted to a particular service into the supply of services. We use our model to estimate the income and substitution effects resulting from changes in relative prices as well as from broad-based increases in the fees paid for services. We specify a CES utility function for physicians, defined over income and leisure. CES preferences have a rich history of use in empirical labour-supply models, beginning with Stern (1976) and Zabalza (1983). This function is general enough to permit unrestricted responses to incentives, and to identify both income and substitution effects, yet it is parsimonious in parameters, allowing for simple and direct interpretations of the results ${ }^{3}$

Our model generates a wage index that measures the marginal return to an hour worked when that hour is optimally allocated across different services. The wage index is a non-linear function of the prices of different services and the elasticity of substitution between those services. As relative prices change, physicians adjust their behaviour, reallocating hours across services through substitution and income effects.

The substitution effects associated with a change in relative prices operate through two separate channels. First, as prices change, physicians alter their supply of services to maximize income for any given number of hours worked. Second, the optimal reallocation of hours across services increases the marginal return to an hour of work causing total hours to increase. Income effects are also present. The optimal allocation of time implies that the price-weighted marginal utility of each service is equated across services. Income effects therefore operate only through total hours worked - they do not affect the relative supply of different services.

Explaining the variation in hours worked and identifying income effects, requires modeling the choice of hours by individual physicians. We do so assuming that physicians choose hours to maximise their utility. Our model is non linear, without a closed form solution for optimal hours. We therefore use numerical methods and the simulated method of moments. We estimate the model taking account of billing ceilings and income taxes.

Our data follow specialist physicians, working in the province of Québec, over a seven year period - between 1996 and 2002. They include detailed information on the number of services provided per quarter by individual physicians, the prices paid for these services

\footnotetext{
${ }^{2}$ This is a variation on the classic multitasking model of Holmstrom and Milgrom (1991) in which workers supply effort across different tasks within an agency framework. Here physicians allocate time across different tasks, producing different services.

3 Stern (1986) provides an excellent discussion of the properties of CES and other utility functions and their uses in labour-supply models.
} 
and physician earnings. These data were matched to time-use survey data provided by the physicians which include information on the number of hours worked per week. The prices for services are set by the government and apply to all physicians in our sample. One important advantage of this feature for the econometrician is that it is reasonable to assume that these prices are exogenous at the physician level. In addition, the Quebec government altered the fee schedule in 2001, changing the relative prices paid for different services. We exploit this variation in prices and incentives to identify our model. To render the model empirically tractable, we apply Hick's composite commodity theorem to aggregate services whose prices moved in parallel across time. We take the group of services provided by each physician as given and estimate the model conditional on that group. This gives sets of physicians distinguished by the number of aggregate services provided: two, three or four.

Our results suggest that physicians do react to incentives. The own-price elasticities vary across services, but are positive and statistically significant for all services. Following the two issues raised above, we highlight both the difference in reaction to changes in the fees for individual services and to broad-based fee increases. Changes in the fees for individual services have positive effects on the supply of those services as substitution effects outweigh income effects. However, broad-based fee increases have negative effects on the supply of services as the income effect dominates. This result is consistent with a developing consensus on the importance of income effects in determining physician behaviour ${ }^{4}$. We discuss the policy implications of our results for using the compensation system to meet short-term demand shocks in health care. We also simulate the effects of the recent decision of the Québec government to increase all fees by $30 \%$. Our simulations point to a this increase leading to a reduction in services of between $1.44 \%$ and $2.20 \%$.

The rest of the paper is organized as follows. The next Section describes the institutional setting related to physician compensation in Quebec and the sources of our data. Section 3 develops the empirical model. Section 5 presents our aggregation strategy, the variables and the descriptive statistics. Section 7 presents our estimation results, while Section 8 discusses policy simulations and the last section discusses possible extensions to the model and concludes.

\footnotetext{
${ }^{4}$ McGuire and Pauly $(1991)$ provide an overview of early evidence.
} 


\section{Institutional details and data description}

\subsection{Physician payment system in Quebec}

In Québec, medical service fees are fixed by the government and applied through the public insurance corporation, known as the Régie de l'assurance maladie du Québe ${ }^{5}$ (RAMQ). Most doctors participate in the public health care system, which means that they receive the totality of their income from the RAMQ - patients pay nothing for their treatment.

Quebec physicians have traditionally been paid according to a fee-for-service system (FFS) 6 Under this system, physicians receive a fee for each service provided. In 1999, the Québec government introduced a Mixed Remuneration (MR) scheme. Under the MR system, physicians received a fixed wage and a reduced fee (relative to the FFS contract) for services provided. Takeup of the MR system was optional. In 2000, approximately $70 \%$ of specialists remained on the FFS system.

Our study concentrates on FFS physicians. These are physicians who did not switch to the MR system. Restricting our analysis to FFS physicians simplifies the empirical analysis. It allows us to concentrate on measuring the reaction of incentives without modelling the selection of a compensation system.7]

In 2001, the government revised the fee schedule paid to physicians for services completed. Fees for individual services increased by between $5 \%$ and $25 \%$, changing the relative prices for services completed and changing the incentives of physicians to complete different services.

\subsection{Data Description and sample construction}

The data used for this study contain information on specialist physicians practicing in Quebec between 1996 and 2002. These data are derived from two sources: the Quebec College of Physicians (CMQ) and the RAMQ. During this time, the CMQ conducted an annual time-use survey of its members. This survey contained information on labour supply behaviour, captured by time spent at work, measured as the average (over the whole year ) number of hours per week and time devoted to seeing patients. Our second source of data comes from the RAMQ administrative files used to pay physicians. These files

\footnotetext{
${ }^{5}$ Free translation: Quebec Insurance Medical Board.

${ }^{6}$ Prior to 1999 , around $92 \%$ of specialist physicians were paid FFS.

${ }^{7}$ There is a potential for selection bias due to physicians endogenously selecting a compensation system. This issue is treated extensively in Fortin, Jacquemet, and Shearer (2017). Extending our model in this direction represents an interesting area for future research.
} 
give information on the medical fees paid to physicians for services completed, and the number of services performed by each physician. These data are available on a quarterly basis for each physician. The data from the CMQ and from RAMQ were matched on the basis of an anonymous payroll number attributed to each physician.

We restrict our sample to specialists who were present both before and after 2001, the year in which prices were changed. This restriction leads us to eliminate 3808 physicians of the 5904 in the initial database. At the same time, we eliminate 183 medical services which were only completed by eliminated physicians. Restricting attention to physicians who remained under the FFS system for the whole sample period eliminates another 590 specialists and 41 services. We also removed services for which prices increased between the years 1996 and 2000. There were 85 such services. We suspect these price changes reflect technological changes and are hence endogenous. Each physician conducts a large number of medical services. To render our empirical model tractable, we aggregated services. With this in mind, we dropped medical services which are not present over the whole sample period - 98 services are concerned. Finally, we dropped the following specialities: electroencephalography, urology, pneumology, rheumatology, physiatry and plastic surgery which represented each between $0.4 \%$ and $2 \%$ of the sample. This removed another 277 specialists and 123 services, leaving 1231 physicians who performed 221 services over a period of 7 years. All services included had fees that remained constant prior to 2001, but increased afterwards. Note that the increase was not immediate in all cases. For some services the agreement between the government and la Fédération des médecins spécialistes du Québec (FMSQ) induced a gradual increase between 2001 and 2002. The specialties include: cardiac and vascular surgery (19 physicians), nephrology (54 physicians), radio-oncology (6 physicians), anesthesiology (41 physicians), endocrinology (30 physicians), gastroenterology (74 physicians), cardiology (149 physicians), pediatrics (93 physicians), internal medicine (127), neurology (63 physicians), general surgery (97 physicians), dermatology (76 physicians), gynecology and obstetrics (127 physicians), orthopedics surgery (84 physicians) and otorhinolaryngology (62 physicians).

\section{Empirical Model}

We develop a model of physician behaviour under linear contracts and multitasking. We focus on the supply side of physician services, explaining differences in the volume of services completed through changes in hours worked, the manner in which those hours are allocated across different services, and supply shocks that render individual physicians 
more or less productive. We ignore demand as a determinant of the number of services completed, assuming that physicians can supply as much or as little of each service as they wish. We feel this is a good first approximation to the health-care market in Canada where health services are paid for by the government and waiting lines exist for most services 8

The production of service $j$ by a physician $k$ is assumed to be a function of hours devoted to it $h_{k, j}$, a service-specific parameter $b_{j}$, and a production shock $\epsilon_{k, j}$. The production shock captures random elements that can be specific to the physician (such as state of health), or the task, and that affect his/her productivity. The output of the physician $k$ in service $j$ is ?

$$
A_{j}=b_{j} h_{j}^{\delta} \epsilon_{j}, \quad \epsilon_{j}>0, b_{j}>0,
$$

where $\delta \in(0,1)$ represents the marginal return to time spent by the physician to provide service $j$. This form of production function exhibits decreasing returns to hours spent in providing services 10

Physician utility is defined over consumption $M$, pure leisure, denoted by $\ell_{p}$, and "on-the-job" leisure, $\ell_{0}$. The latter includes all work-related activities apart from seeing patients, including: teaching, research and administrative tasks. These activities are not remunerated under a FFS scheme ${ }^{11}$ Physician preferences are assumed to be CES (with equal shares), which is general enough to permit unrestricted responses to incentives, yet parsimonious in parameters, allowing for simple and direct interpretations of the results:

$$
U\left(M, \ell_{0}, \ell_{p}\right)=\left(M^{\rho}+\ell_{o}^{\rho}+\ell_{p}^{\rho}\right)^{\frac{1}{\rho}}, \quad \rho<1 .
$$

Here $\ell_{o}=h_{t}-h_{s}, h_{t}$ is total hours spent at work and $h_{s}$, denotes time spent providing services. Pure leisure is $\ell_{p}=T-h_{t}$ with $T$ the maximum amount of time available.

We present the model for the case of $J$ services, which we take as fixed (see assumption

\footnotetext{
${ }^{8}$ We also ignore institutional constraints (such as access to services or operating rooms) as determinants of the number of services completed. We have no information on the particular constraints in place for different hospitals, nor do we have information on the hospital at which a given physician is working.

${ }^{9}$ To simplify notation, we suppress the physician's subscript $k$, until Section 7 on estimation.

${ }^{10}$ The assumption of decreasing returns ensures that a finite, interior solution exists for hours worked but rules gains from specialization in the completion of certain services. One way to incorporate such effects is to allow $b_{j}$ to depend on past experience. Somé (2016) estimates such a model and discusses its policy implications for long-term supply and training physicians.

${ }^{11}$ Since such activities do not generate income, we assume that they increase utility, as in Fortin, Jacquemet, and Shearer (2017). For example, performing teaching or research activities may increase a physician's influence and prestige.
} 
A1, below). The budget constraint is given by:

$$
M=\sum_{j=1}^{J} \alpha_{j} A_{j}+y
$$

where $\alpha_{j}$ represents the fee paid for service $A_{j}$ and $y$ is the non-labour income. Substituting (3) into (2), taking account of (1) and the definition of leisure, we rewrite utility as:

$$
U=\left[\left(\sum_{j=1}^{J} \alpha_{j} b_{j} h_{j}^{\delta} \epsilon_{j}+y\right)^{\rho}+\left(h_{t}-h_{s}\right)^{\rho}+\left(T-h_{t}\right)^{\rho}\right]^{\frac{1}{\rho}}
$$

where

$$
\sum_{j=1}^{J} h_{j}=h_{s}
$$

We list the key assumptions that we impose to simplify the model's resolution and the empirical analysis:

A1. Exogenous Service Mix: A key assumption of the model is that the group of services that a particular physician provides is exogenously fixed. This is equivalent to assuming that each physician is trained to provide a fixed number $J$ of services. It allows us to search for interior solutions that examine how the supply of those services varies as prices change, ignoring services outside of this set. We ignore the decision to provide certain services and not others 13

A.2 Common Shocks: We assume common shocks across services for a given physician: $\epsilon_{j}=\epsilon_{i}=\epsilon$ for $i, j=\{1,2, \ldots, J\}$. As such, we interpret the production shock purely in terms of elements that affect the physician and his/her productivity across all services. This can be due to elements affecting a physician's personal health. It can also reflect physician ability (or inherent productivity) which is constant across periods. Common shocks simplify the estimation as they drop out of the optimization

\footnotetext{
${ }^{12}$ Note that this budget constraint accounts only for FFS contracts. An interesting extension of the model would be to have a budget constraint general enough to account for both FFS and Mixed remuneration contracts.

${ }^{13} \mathrm{~A}$ more general model would examine the choice of which services to provide and allow for corner solutions - possibly due to demand shocks - to explain the fact that certain services are not provided.
} 
problem for allocating time across services. Since the shock affects physician productivity independent of the service completed, only hours worked decisions are affected by the shock. An alternative would be to allow for demand shocks that vary across services 14

A.3 Perfectly Elastic Demand for Services: We rule out any demand shocks as determinants of the observed number of services provided. This is a strong assumption, but one that allows us to focus completely on physician behaviour.

A.4 Full Information for physicians: The physician observes $\epsilon$, the price of each service, and the technology parameters $b_{j}$, before choosing hours. Given the restriction to common shocks that represent physician health or ability, it seems reasonable to assume that the physician observes the value of the shock before selecting hours of work.

A.5 Stationary distribution of shocks: The mean and variance of the distribution of shocks are constant over time. Our data takes the general form of a before-after natural experiment. Given prices are revised annually, any change in unobservable shocks is not separately identified from the effect of the change in prices. Given our interpretation of the shocks as a health shock, drawn across a relatively broad population of physicians, we feel comfortable in assuming that its general characteristics do not change over time.

A.6 Absence of technological change: We assume that the $b_{j}$ parameters are constant through time, ruling out technological change. Again, the before-after nature of our data requires ruling out changes in elements that might be correlated with prices. This step is also necessary for aggregation as it allows us to estimate a constant aggregate $\tilde{b}$ that is common to all services within the aggregated group. While this is obviously an approximation, given the relatively short panel - and the benefits that it accords in terms of aggregation - we feel that this step is justified.

A.7 Exogenous Participation: We assume that participation decisions are independent of potential physician productivity, $\epsilon$. This allows us to ignore modelling the participation decision in estimating the model, focussing solely on the choice of hours worked and services provided.

\footnotetext{
${ }^{14}$ An agency interpretation would allow for service-specific shocks, perhaps due to the complexity of individual cases and asymetric information. Physicians could then hide low effort levels behind low values of production shocks, generating agency costs. We discuss this, and other possible extensions, further in the conclusion of the paper.
} 
The physician chooses total time at work, $h_{t}$, hours devoted to providing services, $h_{s}$, and the manner that those hours are allocated across different services, $h_{j}$, after having observed the value of the productivity shock $\epsilon$.

To solve the model, we note that hours devoted to service $j$ only enter (4) through the first term (income) while total time at work $h_{t}$ only enters the second and the third terms. Optimizing over these variables, for a fixed $h_{s}$, gives closed-form solutions. We therefore proceed conditionally. We fix $h_{s}$ and maximize with respect to $h_{j}$ and $h_{t}$. We denote these solutions $\hat{h}_{j}\left(h_{s}\right), \hat{h}_{t}\left(h_{s}\right)$. We then substitute the optimal values, $\hat{h}_{j}\left(h_{s}\right)$ and $\hat{h}_{t}\left(h_{s}\right)$ into (4) to concentrate utility as a function of $h_{s}$, which we can maximize to find optimal hours devoted to services.

To maximize (4) with respect to $h_{1}$, we substitute the constraint (5) into (4). The firstorder condition for $h_{1}$ is:

$$
\alpha_{1} b_{1} h_{1}^{\delta-1}-\alpha_{J} b_{J}\left(h_{s}-h_{1}-h_{2}-\ldots h_{J-1}\right)^{\delta-1}=0
$$

Standard algebra shows that, conditional on clinical hours $h_{s}$, the optimal time spent providing service $j$ is:

$$
\hat{h}_{j}\left(h_{s}\right)=\frac{\widetilde{P}_{j}}{\sum_{i=1}^{J} \widetilde{P}_{i}} h_{s}
$$

where

$$
\widetilde{P}_{j}=\left(\alpha_{j} b_{j} \epsilon_{j}\right)^{\frac{1}{1-\delta}} .
$$

Maximizing with respect to $h_{t}$, we have the following first-order condition:

$$
\left(h_{t}-h_{s}\right)^{\rho-1}-\left(T-h_{t}\right)^{\rho-1}=0,
$$

which gives

$$
\hat{h}_{t}\left(h_{s}\right)=\frac{T+h_{s}}{2} .
$$

Substituting from (7) and (8) back into (4) gives the (conditional) indirect utility as a function of $h_{s}$ :

$$
V\left(h_{s}\right)=\left[\left(w h_{s}^{\delta} \epsilon+y\right)^{\rho}+2^{1-\rho}\left(T-h_{s}\right)^{\rho}\right]^{\frac{1}{\rho}}
$$


where

$$
w=\left(\sum_{j=1}^{J} \widetilde{P}_{j}\right)^{1-\delta}
$$

determines the marginal return to an hour worked when that hour is optimally allocated across services, given relative prices. It is important to note that $w$ is not a wage in the traditional sense, but a wage index. Earnings are not linear in hours worked. Rather hours are an input to the production of services and hence have decreasing marginal productivity. Notice as well, each hour worked is replicated and distributed across different services. This reflects the decreasing returns to the production of any given service and common shocks giving rise to interior solutions within the set of services that the physician provides - in the absence of increasing returns there are no gains to specialization among services.

The physician's optimal hours spent seeing patients, $h_{s}^{*}$ solves

$$
w \delta h_{s}^{* \delta-1} \epsilon\left(w h_{s}^{* \delta} \epsilon+y\right)^{\rho-1}-2^{1-\rho}\left(T-h_{s}^{*}\right)^{\rho-1}=0 .
$$

The second-order condition is

$$
\begin{array}{r}
V_{h_{s} h_{s}}=w \delta(\delta-1) h_{s}^{* \delta-2}\left(w h_{s}^{* \delta}+y\right)^{\rho-1}+(\rho-1)\left(w \delta h_{s}^{* \delta-1}\right)^{2}\left(w h_{s}^{* \delta}+y\right)^{\rho-2} \\
+2^{1-\rho}(\rho-1)\left(T-h_{s}^{*}\right)^{\rho-2}<0
\end{array}
$$

since $\delta \in(0,1)$ and $\rho<1$.

While (11) does not give rise to an explicit functional form for $h_{s}^{*}$, it can be solved numerically. Upon doing so, the optimal values of $h_{j}^{*}=\hat{h}_{j}\left(h_{s}^{*}\right)$ can be solved by evaluating equations (7), at $h_{s}^{*}$. With common shocks (Assumption A.2), the optimal number of services is given by

$$
A_{j}^{*}=b_{j}\left[\frac{P_{j}}{\sum_{i=1}^{J} P_{i}}\right]^{\delta} h_{s}^{* \delta} \epsilon,
$$

where

$$
P_{j}=\left(\alpha_{j} b_{j}\right)^{\frac{1}{1-\delta}}
$$

represents the non-random counterpart of $\widetilde{P}_{j}$. 


\section{Comparative statics}

A physician's reaction to incentives can be analyzed using comparative techniques. Fees changes imply income and substitution effects for the supply of services. These effects operate through the time allocated to different services within the context of our model. They operate through multiple channels since physicians choose the number of hours to devote to services and the manner in which those hours are allocated across services. We present the relevant equations in the text. Complete derivations are given in the Appendix A.1.

\subsection{Own-price elasticities}

The own-price elasticity captures how physicians alter the supply of service $j$ in response to a change in its price relative to the prices of the other services. We concentrate on the elasticity of hours devoted to service $j i^{15}$ This is given by

$$
\eta_{h_{j}, \alpha_{j}}=\underbrace{\left[\frac{1}{(1-\delta)} \frac{\sum_{i \neq j} P_{i}}{\sum_{i} P_{i}}-\frac{\alpha_{j} A_{j} \delta M^{\rho-1}}{h_{s}^{2} F_{h_{s}}}\right]}_{\text {Substitution effect }}+\underbrace{\frac{\alpha_{j} A_{j}}{y} \eta_{h_{s}, y}}_{\text {Income effect }}
$$

The first term represents the substitution effect which is positive - since $F_{h_{s}}$ is negative from the second-order condition - and the second term represents the income effect, which is negative. The substitution effect is composed of two parts. First, conditional on hours, $h_{s}$, physicians allocate more time towards those services for which the price has risen. From (7),

$$
h_{j}=\frac{P_{j}}{\sum_{i} P_{i}} h_{s},
$$

hence (holding $h_{s}$ constant)

$$
\left.\frac{\alpha_{j}}{h_{j}} \frac{d h_{j}}{d \alpha_{j}}\right|_{h_{s}}=\frac{1}{(1-\delta)} \frac{\sum_{i \neq j} P_{i}}{\sum_{i} P_{i}}>0
$$

\footnotetext{
${ }^{15}$ The elasticity for services is proportional to the elasticity for hours:

$$
\eta_{A_{j}, \alpha_{j}}=\delta \eta_{h_{j}, \alpha_{j}} .
$$
}


the first term of the substitution effect.

The second component of the substitution effect results from the wage index increasing (through the reallocation of hours across services subsequent to the change in relative prices) which increases the marginal return to an hour of work. These additional hours are then allocated across different services optimally, including the service whose price has changed. This term depends on $\rho$ which determines how total hours adjusts.

\subsection{Cross-price elasticities}

The expression for the cross-price elasticity is

$$
\begin{gathered}
\eta_{h_{j}, \alpha_{i}}=\underbrace{-\left[\frac{1}{(1-\delta)} \frac{P_{i}}{\sum_{l} P_{l}}+\frac{\delta \alpha_{i} A_{i} M^{\rho-1}}{h_{s}^{2} F_{h_{s}}}\right]}_{\text {Substitution effect }}+\underbrace{\frac{\alpha_{i} A_{i}}{y} \eta_{h_{j}, y}}_{\text {Income effect }} \\
\eta_{A_{j}, \alpha_{i}}=\delta \eta_{h_{j}, \alpha_{i}}
\end{gathered}
$$

for $\imath=\{1,2, \ldots, J\}$. Again the substitution effect has two components. The change in relative prices causes physicians to substitute away from services whose relative price has decreased, but the resulting increase in $w$ leads to an increase in hours worked which is distributed across all services, including those with lower prices. The overall crossprice substitution effect is ambiguous. Notice, as well, the substitution effects are not symmetric, even conditional on $h_{s}$. This is due to the nonlinearities in the production of services that enter the budget constraint (e.g., Kalman and Intriligator, 1973; Blomquist, 1989). Changes in prices cause first and second-order effects that determine the elasticity of substitution. These effects are shown in Figure 1. The figure shows the substitution effects, for a given level of $h_{s}$. The physician chooses $h_{1}$ and $h_{2}$ to maximize income along $h h^{\prime}$. Iso-income lines are convex due to decreasing returns of $h_{i}$ devoted to any service. A change in relative prices rotates the isoincome line, but also alters its convexity. The substitution effect is then completed by an adjustment of $h_{s}$ as $w$ changes with the change in prices. The homogeneity of the iso-income curves ensures a constant relative supply of $h_{1}$ and $h_{2}$ through this second phase. 
Figure 1: Iso-income maps for $h_{1}$ and $h_{2}$

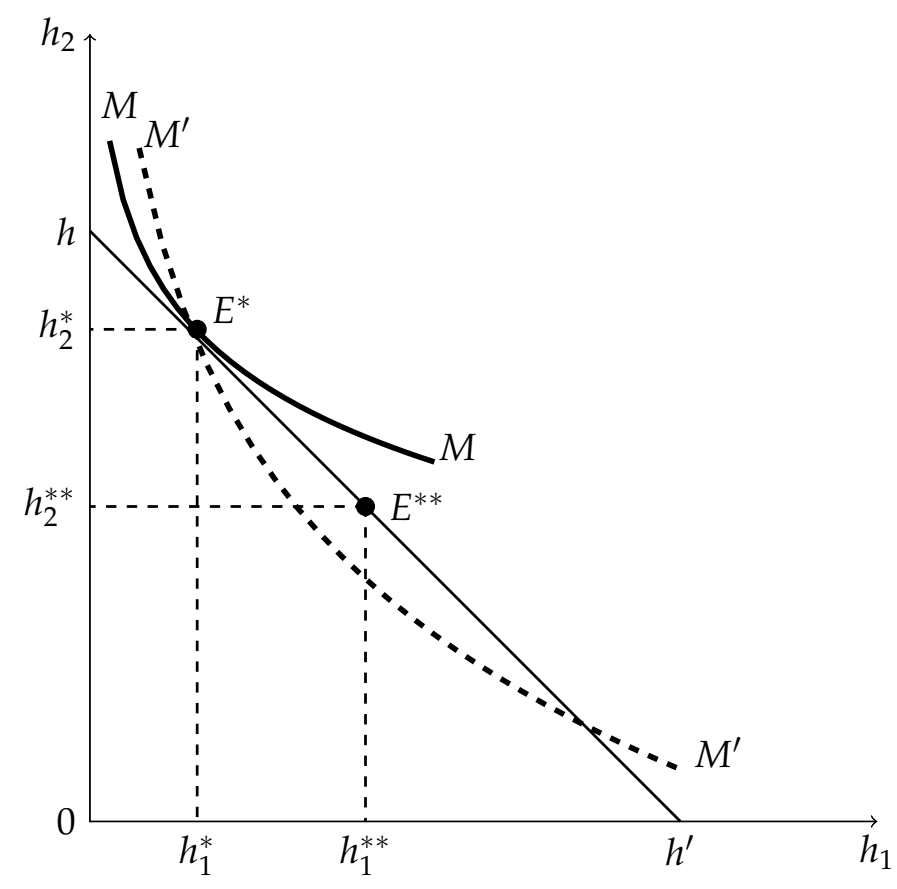

\subsection{Wage index elasticities}

As discussed in the introduction, a major concern of our paper is to analyse the impact of a change in a proportional increase in all prices on a physician labour supply. From (11), this can be approximated by the effect in the wage index on clinical hours worked, as given by:

$$
\eta_{h_{s}, \omega}=\frac{\omega}{h_{s}}[-\underbrace{\frac{\delta h_{s}^{\delta-1}\left(\omega h_{s}^{\delta}+y\right)^{\rho-1}}{F_{h_{s}}}}_{\text {Substitution Effect }}+\underbrace{\frac{(1-\rho) \delta \omega h_{s}^{2 \delta-1}\left(\omega h_{s}^{\delta}+y\right)}{F_{h_{s}}}}_{\text {Income Effect }}]
$$

where

$$
F_{h_{s}}=w \epsilon \delta(\delta-1) h_{s}^{\delta-2} M^{\rho-1}+(\rho-1)\left(w \delta h_{s}^{\delta-1} \epsilon\right)^{2} M^{\rho-2}+2^{1-\rho}(\rho-1)\left(T-h_{s}\right)^{\rho-2}<0 .
$$


The substitution effect is positive and reflects the compensated effect of a change in the wage index on total clinical hours, while the income effect is negative as (pure and onthe-job) leisure is a normal good.

Using (7), the effect of an increase in $\omega$ on hours devoted to a given service can be calculated as:

$$
\frac{\partial h_{j}}{\partial \omega}=\frac{P_{j}}{\sum_{i=1}^{I} P_{i}} \frac{\partial h_{s}}{\partial \omega} .
$$

Here the first term is homogeneous of degree 0 in prices and hence unaffected by a broad increase in all prices. In consequence, the elasticity of $h_{j}$ with respect to $\omega$ is the same as the elasticity of $h_{s}$ with respect to $\omega$ :

$$
\begin{aligned}
\frac{\partial h_{j}}{\partial \omega} \frac{\omega}{h_{j}} & =\frac{P_{j}}{\sum_{i=1}^{I} P_{i}} \frac{\partial h_{s}}{\partial \omega} \frac{\omega}{\frac{P_{j}}{\sum_{i=1}^{I} P_{i}} h_{s}} \\
& =\frac{\partial h_{s}}{\partial \omega} \frac{\omega}{h_{s}}
\end{aligned}
$$

Similarly,

$$
\frac{\partial A_{j}}{\partial \omega} \frac{\omega}{A_{j}}=\delta \frac{\partial h_{s}}{\partial \omega} \frac{\omega}{h_{s}} .
$$

\section{Aggregation and Variable Construction}

Conditional on $h_{s}$, only relative prices matter for determining the amount of time devoted to a particular service, hence the supply of services for which the relative price is constant through time will not change with respect to each other. They can therefore be treated as one service, the price of which is their price increase through time and the aggregate is the income generated by the supply of those services. Formally, we apply the Hick's composite-commodity theorem - the derivation within our context is in the Appendix A.2. As shown in Section A.2.1 of the appendix, the productivity parameters $b$ of the aggregated services represent weighted averages of the individual service parameters. The weights being the base-period prices.

Our data cover a period during which the Quebec government changed the relative prices paid to physicians for the completion of medical services. To aggregate services, we considered the (geometric) average price increase of each service between the years 
2000 and 2002, rounded to the nearest $5 \%$. This provides six groups of services, whose prices increased (on average) by $0,5,10,15,20$ and 25 percent.

Let $\alpha_{j}^{t}$ be the nominal price of service $j$ in year $t$, for $t=1996,1997,1998,1999,2000$, 2001, 2002. Since prices are constant between 1996 and 2000, we treat 2000 as the base year. We calculate $\theta$ based on the geometric average growth rate of the price of service $j$ between $t=2000$ and $t=2002$ (see Appendix A.2 for more details). Denote this geometric average by $\lambda$, then

$$
\lambda_{j}=\text { Round }_{0.05}\left[\left(\frac{\alpha_{j}^{2002}}{\alpha_{j}^{2000}}\right)^{0.5}-1\right]
$$

where Round.05 denotes the rounding operator. All services with the same $\lambda$ were aggregated into the same group. This provides six groups of services, whose prices increased by $0,5,10,15,20$ and 25 percent. If there are $m>2$ services with the same $\lambda$, their composite service volume - provided by physician $i$ - is calculated as $\sum_{j=1}^{m} \alpha_{j}^{2000} A_{i j}^{t}$, where $A_{i j}^{t}$ is the number of services $j$ performed by physician $i$ at time $t$. The nominal price of composite service $j$ after one period (in the year 2001) is then $\theta_{j, 01}=\lambda_{j}+1$. The nominal price in year 2002 is $\theta_{j, 02}=\lambda_{j}^{2}+1$. We then convert nominal prices to real prices for each period, by dividing by a price index.

Table 1: Distribution of composite services

\begin{tabular}{c|c|c|c} 
Composite service & Average price increase (\%) & \% of Services & Number of acts \\
\hline \hline 1 & $0 \%$ & $59.38 \%$ & 57 \\
2 & $5 \%$ & $29.17 \%$ & 28 \\
3 & $10 \%$ & $7.29 \%$ & 7 \\
4 & $15 \%$ & $2.08 \%$ & 2 \\
5 & $20 \%$ & $1.04 \%$ & 1 \\
6 & $25 \%$ & $1.04 \%$ & 1 \\
\hline \hline Total & & $100.00 \%$ & 96
\end{tabular}

The distribution of composite services is presented in Table 1. Our composite service 1 is an aggregation of medical acts for which the price remained constant for the whole sample period. This group contains $59.38 \%$ of services. The composite service 2 contains services whose prices increased by 5\% between 2000 and 2002. This amounts to $29.17 \%$ of services. Composite service 3 contains services whose prices rose by $10 \%$ and represents $7.3 \%$ of services. The composite service 4 is the group of medical services whose prices 
increased by $15 \%$. This represents $2.08 \%$ of services. The composite service 5 represents services whose prices increased by $20 \%$. It represents $1 \%$ of services. The composite service 6 represents services whose prices increased by $25 \%$. It represents $1 \%$ of services.

\subsection{Earnings}

Each physician's earnings are calculated as the sum of (aggregate) services that the physician provided in a given year multiplied by the price of those aggregate services. In our sample each physician did not necessarily provide each of the 6 aggregate services. In line with assumption A1, we take the set of aggregate services provided by a given physician as fixed ${ }^{16}$ We then classify physicians into groups, depending on the set of medical services provided. This gives 3 disjoint groups of physicians: physicians who provided 2 services, physicians who provided 3 services and physicians who provided 4 services $\mid$\begin{tabular}{ll}
$\mid 17$ & 18 \\
\hline
\end{tabular} A complete description of the construction of earnings is given in the Appendix A.3.

\section{Descriptive Statistics}

Table 2 shows summary statistics on the main variables of interest for our model: hours worked, prices and earnings. We provide statistics on each for each period of the sample data, separated by the number of services provided. Hours worked are reported on a weekly basis. Earnings are annual and in thousands of dollars.

The prices of all goods are the same before the price increases in the year 2000. This reflects the fact that these are the prices of the aggregate services (measured by the revenue generated from those services). Under the aggregation theorem, their prices are equal to the rate of increase of the prices within the relevant group of services. As all prices were stable before the year 2000, their nominal prices are equal to one for those years. The variation across years reflects changes in the rate of inflation. The price increases are evident in years 2001-2002, raising average earnings in the process. Subsequent to the fee changes, physician incomes increased (21\% for those providing 2 services , $6.9 \%$ for those providing 3 services and $21.2 \%$ for those providing 4 services). There is a slight decrease in clinical hours worked between the years 2000 and 2002, in the order of 3.5\% for those

\footnotetext{
${ }^{16}$ One interpretation of this is as a short-term phenomenon. Physicians are trained to perform a certain number of services and we take the set of those services as fixed.

${ }^{17}$ Grouping physicians avoids censored data that would arise from physicians not providing some services.

${ }^{18}$ Note that within each group, however, each physician does not necessarily provide the same services. For example, within the group of physicians who provided 2 services are found physicians who provided services 1 and 2 as well as physicians who provided services 1 and 3 .
} 
Table 2: Descriptive statistics : Prices, Earnings and Hours

\begin{tabular}{|c|c|c|c|c|c|c|c|c|c|c|}
\hline \multicolumn{11}{|c|}{ Physicians providing 2 services } \\
\hline Year & Obs & \multicolumn{6}{|c|}{ Prices } & Annual & Clinical & Weeks \\
\hline & & 1 & 2 & 3 & 4 & 5 & 6 & $\left(000^{\prime} \mathrm{s}\right)$ & (weekly) & \\
\hline 1996 & 197 & 1.104 & 1.104 & 1.104 & - & - & - & 96.27 & 42.02 & 45.74 \\
\hline 1997 & 201 & 1.087 & 1.087 & 1.087 & - & - & - & 93.68 & 46.47 & 46.16 \\
\hline 1998 & 188 & 1.057 & 1.057 & 1.057 & - & - & - & 96.55 & 43.12 & 46.06 \\
\hline 1999 & 192 & 1.035 & 1.035 & 1.035 & - & - & - & 95.75 & 44.74 & - \\
\hline 2000 & 189 & 1.017 & 1.017 & 1.017 & - & - & - & 93.32 & 44.98 & - \\
\hline 2001 & 168 & 1.005 & 1.055 & 1.106 & - & - & - & 106.94 & 44.15 & - \\
\hline 2002 & 165 & 1.000 & 1.103 & 1.21 & - & - & - & 112.94 & 43.39 & 45.82 \\
\hline \multicolumn{11}{|c|}{ Physicians providing 3 services } \\
\hline Year & Obs & \multicolumn{6}{|c|}{ Prices } & $\begin{array}{c}\text { Annual } \\
\text { Earnings }\end{array}$ & $\begin{array}{l}\text { Clinical } \\
\text { Hours }\end{array}$ & Weeks \\
\hline & & 1 & 2 & 3 & 4 & 5 & 6 & $\left(000^{\prime} \mathrm{s}\right)$ & (weekly) & \\
\hline 1996 & 191 & 1.104 & 1.104 & 1.104 & - & 1.104 & 1.104 & 151.35 & 41.24 & 46.20 \\
\hline 1997 & 180 & 1.087 & 1.087 & 1.087 & - & 1.087 & 1.087 & 153.82 & 45.91 & 46.64 \\
\hline 1998 & 177 & 1.057 & 1.057 & 1.057 & - & 1.057 & 1.057 & 151.88 & 42.40 & 46.38 \\
\hline 1999 & 190 & 1.035 & 1.035 & 1.035 & - & 1.035 & 1.035 & 140.65 & 43.07 & - \\
\hline 2000 & 191 & 1.017 & 1.017 & 1.017 & - & 1.017 & 1.017 & 141.98 & 43.74 & - \\
\hline 2001 & 179 & 1.005 & 1.055 & 1.106 & - & 1.206 & 1.256 & 149.43 & 44.22 & - \\
\hline 2002 & 175 & 1.000 & 1.103 & 1.210 & - & 1.440 & 1.563 & 151.81 & 42.59 & 46.25 \\
\hline \multicolumn{11}{|c|}{ Physicians providing 4 services } \\
\hline Year & Obs & \multicolumn{6}{|c|}{ Prices } & $\begin{array}{c}\text { Annual } \\
\text { Earnings }\end{array}$ & $\begin{array}{l}\text { Clinical } \\
\text { Hours }\end{array}$ & Weeks \\
\hline & & 1 & 2 & 3 & 4 & 5 & 6 & $(000$ 's) & (weekly) & \\
\hline 1996 & 197 & 1.104 & 1.104 & 1.104 & 1.104 & 1.104 & - & 82.86 & 42.40 & 45.25 \\
\hline 1997 & 201 & 1.087 & 1.087 & 1.087 & 1.087 & 1.087 & - & 81.18 & 48.84 & 45.48 \\
\hline 1998 & 188 & 1.057 & 1.057 & 1.057 & 1.057 & 1.057 & - & 81.30 & 44.97 & 45.04 \\
\hline 1999 & 192 & 1.035 & 1.035 & 1.035 & 1.035 & 1.035 & - & 79.61 & 48.17 & - \\
\hline 2000 & 189 & 1.017 & 1.017 & 1.017 & 1.017 & 1.017 & - & 78.72 & 49.27 & - \\
\hline 2001 & 168 & 1.005 & 1.055 & 1.106 & 1.156 & 1.206 & - & 89.81 & 48.80 & - \\
\hline 2002 & 165 & 1.000 & 1.103 & 1.210 & 1.323 & 1.440 & - & 95.48 & 45.90 & 44.2 \\
\hline
\end{tabular}


providing 2 services, $2.6 \%$ for those providing 3 services and $6.8 \%$ for those providing 4 services. These reductions are consistent with the presence income effects. Physicians spend part of the fee increase on consuming extra leisure.

Given earnings are reported on an annual basis and hours on a weekly basis, we convert earnings to weekly values by dividing by reported annual weeks worked. This is somewhat problematic due to the fact that annual weeks worked is not reported for three years of the survey. In an effort to keep as much data as possible, we therefore divide annual earnings by the average number of weeks worked during the years for which weeks are observed: 45.9519

\section{Estimation}

To estimate the parameters, we match the first moments of log earnings earned on each service, the first moment of the log hours in each period and the second moment of the $\log$ total earnings. The log earnings from service $j$ for physian $k$ in period $t$ are given by

$$
\ln \mathcal{E}_{k, j, t}=\ln \left(P_{j_{t}}\right)-\delta \ln \left(\sum_{j} P_{j, t}\right)+\delta \ln h_{k, t}+\epsilon_{k, t}
$$

where $P_{j_{t}}=\left(b_{j} \alpha_{j_{t}}\right)^{\frac{1}{1-\delta}}$. The log total earnings in period $t$ for a physician providing $J$ services are

$$
\ln \mathcal{E}_{k, t}=\ln \omega_{t}+\delta \ln h_{k, t}+\epsilon_{k, t}
$$

where $\omega_{t}=\left(\sum_{j=1}^{J} P_{j, t}\right)^{(1-\delta)}$.

We allow the productivity parameters of the services that all physicians offer to differ, depending on the mixture of services the physician provides. For example, for physicians providing 2 services, all physicians provide service 1 and either service 2 or service 3 . We let $b_{1,12}$ denote the parameter $b_{1}$ among physicians providing services 1 and 2 , and $b_{1,13}$ denotes the parameter $b_{1}$ among physicians providing services 1 and 3 . The moment equations on earnings identify the parameters the service-specific productivity parameters $b_{j}$, the substitution parameter $\delta$, and the variance of shocks $\sigma_{\epsilon}^{2}$. No information on the parameter $\rho$ is available from earnings.

\footnotetext{
${ }^{19}$ To investigate the accuracy of this approximation, we compared the earnings per week so constructed, with actual earnings per week for those years that the actual weeks worked was available. We then regressed the two measures to see how closely our approximate measure predicts the actual earnings per week in those years. The slope coefficient is estimated to be .978 and a test of the hypothesis that the coefficient equals one is not rejected at the 5\% significance level.
} 
We add the hours equation (11) to explain observed variation in hours worked in each period and identify $\rho$. We use numerical methods to solve for hours, setting non-labour income to zero ${ }^{20}$ We use * to denote values that are generated within the model and we note that $h_{s}^{*}$ solves

$$
w \delta h_{s}^{* \delta-1} \epsilon\left(h_{s}^{* \delta} \epsilon\right)^{\rho-1}-2^{1-\rho}\left(T-h_{s}^{*}\right)^{\rho-1}=0,
$$

which depends on a vector of service prices $\mathcal{P}$ (through $\omega$ ), the random shock $\epsilon$, and unknown parameters, which we denote $\Gamma_{J}$, indexed by the total number of services provided:

$$
\begin{array}{ll}
\Gamma_{2}=\left(\rho, b_{1,1 j}, b_{j}, \delta, \sigma_{\epsilon}^{2}\right) & \text { for } j=2,3 ; \\
\Gamma_{3}=\left(\rho, b_{1,12 j}, b_{2,12 j}, b_{j}, \delta, \sigma_{\epsilon}^{2}\right) & \text { for } j=3,4 ; \\
\Gamma_{4}=\left(\rho, b_{1,123 j}, b_{2,123 j}, b_{3,123 j}, b_{j}, \delta, \sigma_{\epsilon}^{2}\right) & \text { for } j=4,5 .
\end{array}
$$

We estimate the model using simulated method of moments (SMM), generating $\epsilon$ from a lognormal distribution. Let $h_{s, t, r}^{*}\left(\Gamma, \mathcal{P}_{t}, \epsilon_{r}\right)$, denote the hours worked that solves (26), given period $t$ prices, $\mathcal{P}_{t}$, and a particular draw of $\epsilon_{r}$. Similarly, $\mathcal{E}_{j, r}^{*}\left(\Gamma, \mathcal{P}_{t}, \epsilon_{r}\right)$ represents the resulting implied earnings on services $j$. Given $N_{t}$ observations in period $t$ and given $N_{r}$ repeated draws: $\epsilon_{1}, \epsilon_{2}, \ldots \epsilon_{N_{r}}$, we calculate the simulated period-t moments, conditional on period- $t$ prices, as

$$
\begin{aligned}
\overline{\ln h_{t}^{*}}\left(\Gamma, \mathcal{P}_{t}\right) & =\frac{1}{N_{t} N_{r}} \sum_{k=1}^{N_{t}} \sum_{r=1}^{N_{r}} \ln h_{k, r, t}^{*}\left(\Gamma, \mathcal{P}_{t}, \epsilon_{r}\right), \\
\overline{\ln \mathcal{E}_{t}^{*}}\left(\Gamma, \mathcal{P}_{t}\right) & =\frac{1}{N_{t} N_{r}} \sum_{k=1}^{N_{t}} \sum_{r=1}^{N_{r}} \ln \mathcal{E}_{k, r, t}^{*}\left(\Gamma, \mathcal{P}_{t}, \epsilon_{r}\right) \\
\overline{\ln \mathcal{E}_{t, j}^{*}}\left(\Gamma, \mathcal{P}_{t}\right) & =\frac{1}{N_{t} N_{r}} \sum_{k=1}^{N_{t}} \sum_{r=1}^{N_{r}} \ln \mathcal{E}_{k, j, r, t}^{*}\left(\Gamma, \mathcal{P}_{t}, \epsilon_{r}\right) \\
\left.\overline{\left(\ln \mathcal{E}_{t}^{*}\right.}\left(\Gamma, \mathcal{P}_{t}\right)\right)^{2} & =\frac{1}{N_{t} N_{r}} \sum_{k=1}^{N_{t}} \sum_{r=1}^{N_{r}}\left(\ln \mathcal{E}_{k, r, t}^{*}\left(\Gamma, \mathcal{P}_{t}, \epsilon_{r}\right)\right)^{2}
\end{aligned}
$$

for services $j=2, \ldots, J$.

We then choose the parameter vector to match the simulated moments for each year to their observed counterparts. Let $\overline{\ln h_{t}{ }^{0}}, \overline{\ln \mathcal{E}_{t}^{o}}, \overline{\ln \mathcal{E}_{t, j^{\prime}}^{o}}$, and $\overline{\left(\ln \mathcal{E}_{t}^{o}\right)^{2}}$, be the observed average

\footnotetext{
${ }^{20}$ Attempts to identify parameters of non-labour income have proved unsuccesful.
} 
values of: the natural logarithm of hours worked by physicians in year $t$, the natural logarithm of earnings in year $t$, the natural logarithm of earnings on service $j$ in year $t$, and the square of natural logarithm of total earnings, respectively.

Given 6 aggregate services, there are $\left(\begin{array}{l}6 \\ J\end{array}\right)$ possible service mixtures among physicians providing $J$ services. Yet only a subset $J^{\circ}$ of these are observed in the sample. Let $q_{j^{\circ}}^{J}$ denote the observed service mix $j^{0}$ among physicians providing $J$ services. Also, let $Q_{J}=$ $\cup_{j^{0} \in J} q_{j^{0}}^{J}$ be the set of service mixtures that is observed for physicians providing $J$ services. Note that $Q_{J}$ has $J^{o}$ elements. ${ }^{21}$

For physicians providing $J$ services, the $(J+2)$ vector of moments for physicians providing service mix $q_{j^{\circ}}^{J} \in Q_{J}$, in year $t$, is given by:

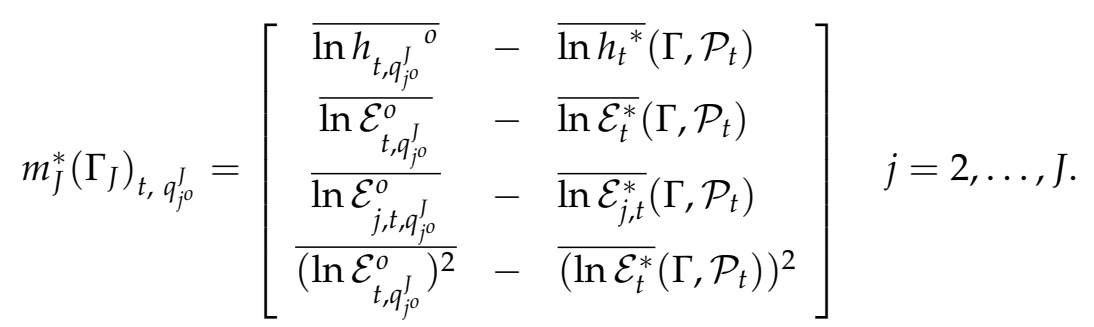

Let $m_{J}^{*}\left(\Gamma_{J}\right)$ be the $\left((J+2) \times J^{o} \times T\right)$ vector of stacked moments for the sample of physicians providing $J$ services. The estimator solves

$$
\widehat{\Gamma_{J}}=\underset{\Gamma_{J}}{\arg \min } m_{J}^{*}\left(\Gamma_{J}\right)^{\prime} \Omega_{J}^{-1} m_{J}^{*}\left(\Gamma_{J}\right)
$$

where $\Omega_{J}$ represents a $\left((J+2) \times J^{o} \times T\right) \times\left((J+2) \times J^{o} \times T\right)$ symmetric weighting matrix for physicians providing $J$ services.

We estimate the model in two steps. In the first step, we set $\Omega$ to be the variancecovariance matrix of observed sample moments. We allow for correlation between moments within a given period among physicians providing the same services, but impose

\footnotetext{
${ }^{21}$ Among physicians providing $J$ services, there is a different moment vector for each set of services provided. For example, for physicians providing 2 services, there is one vector for physicians providing services 1 and 2 and another vector for services providing services 1 and $3 . Q_{2}=\{(1,2),(1,3)\} ; Q_{3}=$ $\{(1,2,3),(1,2,5),(1,2,6)\} ; Q_{4}=\{(1,2,3,4),(1,2,3,5)\}$.
} 
independence across periods and across $q_{j^{0}}^{J}: \Omega$ is block diagonal, with block $t, q_{j^{\circ}}$ given by

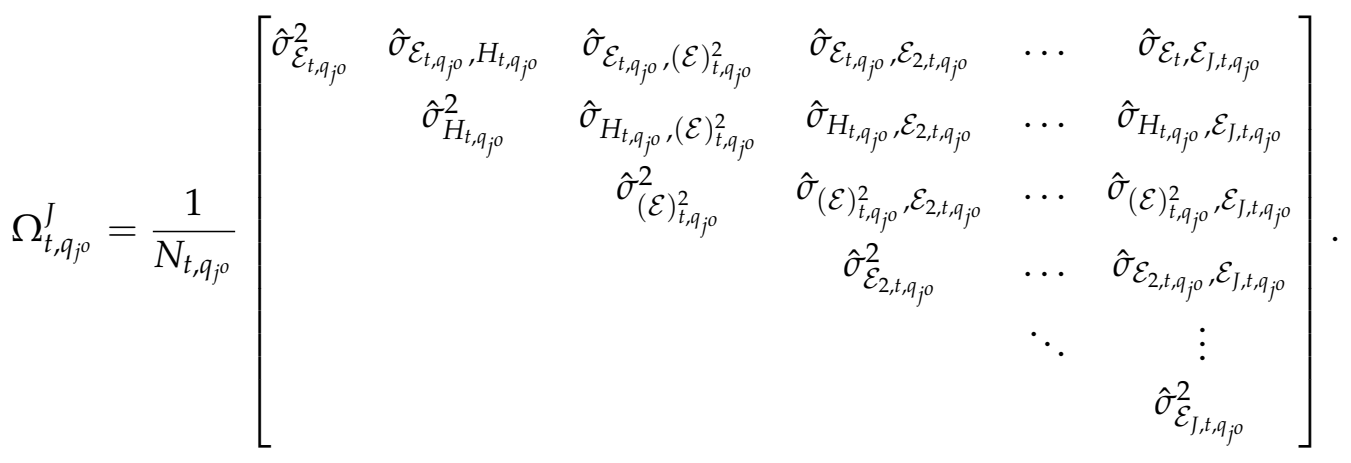

Here, $\hat{\sigma}_{x_{t, q} q_{0}}^{2}$ represents the sample variance of $\ln x$ in period $t$, among physicians supplying services in group $j^{o}$. Similarly, $\hat{\sigma}_{x_{t, q_{j}}, y_{t, q} q_{j 0}}$ represents the sample covariance between $\ln x$ and $\ln y$. We denote the resulting estimator $\widehat{\Gamma}_{1}$. Similar to pooled estimators, correlation across periods due to random individual-specific effects is ignored and causes an efficiency loss. Notice, however, that individual-specific effects will be captured in $\epsilon$; any correlation with hours will be accounted for through (26). The resulting estimators are consistent but inefficient.

In the second step, we use $\widehat{\Gamma}_{1}$ to construct the weighting matrix of moments across periods, allowing for correlation across periods due to random individual-specific effects. Let $\hat{\epsilon}_{q, 1}$ denote the $\left((J+2) T_{k} \times 1\right)$ residual vector for individual $k$, from the first-stage estimates. $T_{k}$ is the number of periods in which individual $k$ worked. Assuming the residual can be decomposed into a term that is independent across time $e_{x, k, t}$ and an individualspecific term, $\eta_{k}$, that is constant across periods but independent across individuals, the covariance between moments $\bar{x}$ in period $t$ and $\bar{y}$ in period $s$ is:

$$
\operatorname{Cov}\left(\bar{x}_{t}, \bar{y}_{s}\right)=\frac{n_{t, s} \sigma_{\eta}^{2}}{n_{t} n_{s}}
$$

where $\sigma_{\eta}^{2}$ is the variance of the individual-specific effect, $n_{t}, n_{s}$ represent the number of observations periods $t$ and $s$ respectively, and $n_{t, s}$ is the number of physicians who worked in both periods.

\subsection{Income Taxes and Billing Ceilings}

In order to estimate the model we take account of the institutional incentives imposed on physicians by the government through income ceilings and taxes. These affect the budget 
constraint and hence hours worked. We describe briefly here the institutions and method. Details are also presented in the Appendix; see also Somé (2016). Note, given we observe gross earnings, we solve for optimal hours given the tax rates and income ceilings. We then match the implied gross earnings that optimal hours implies to observed earnings.

\section{Billing Ceilings:}

Prior to 1999, the government of Quebec imposed half-yearly billing ceiling $2^{22}$ on physicians. Payment for billed services, beyond the ceiling, was reduced by $75 \%$.

Let $\bar{E}_{w, c}$ denote the weekly income ceiling ${ }^{23}$ The weekly earnings derived from seeing patients,

$$
\mathcal{E}=w h_{s}^{\delta} \epsilon
$$

allows us to calculate the number of weekly hours needed to obtain $\bar{E}_{w, c}$,

$$
\bar{h}_{s, c}=\left(\frac{\bar{E}_{w, c}}{w \epsilon}\right)^{1 / \delta} .
$$

Let $\tau_{c}=0.75$ be the penalty for exceeding the billing ceiling. The potential earnings (or budget constraint) of the physician is then given by

$$
\text { Earnings }=\left\{\begin{array}{ccc}
w h_{s}^{\delta} \epsilon & \text { if } & h_{s} \leq \bar{h}_{s, c} \\
\left(1-\tau_{c}\right) w h_{s}^{\delta} \epsilon & \text { if } & h_{s}>\bar{h}_{s, c} .
\end{array}\right.
$$

The penalty implies a kink in potential earnings at $\bar{h}_{s, c}$ which depends on both $\delta$ and $\epsilon$.

Income Taxes: The budget constraint becomes more complex when taking account of income taxes. We calculated the marginal tax rates, including both provincial and federal

\footnotetext{
${ }^{22}$ The income ceilings for specialists was set at 150 thousand CAN dollars per semester between 1996 and 1999, except for neurologists, the ceiling was 142.5 thousand CAN dollars per semester.

${ }^{23}$ We convert to a weekly ceiling by dividing the annual income ceiling by the average weeks worked per year in the sample. The average weeks worked per year is 45.83 for physicians providing 2 services, 45.70 for physicians providing 3 services and 44.2 for physicians providing 4 services.
} 
income taxes. For example, in 2001 the tax structure is:

$$
\text { Tax rate }=\left\{\begin{array}{cll}
\tau_{1}=33 \% & \text { if } \quad 0 \leq E<26,000 \\
\tau_{2}=37.25 \% & \text { if } \quad 26,000 \leq E<30,754 \\
\tau_{3}=43.25 \% & \text { if } \quad 30,754 \leq E<52,000 \\
\tau_{4}=46.5 \% & \text { if } \quad 52,000 \leq E<61,509 \\
\tau_{5}=50.5 \% & \text { if } \quad 61,5090 \leq E<100,000 \\
\tau_{6}=53.5 \% & \text { if } \quad E \geq 100,000 .
\end{array}\right.
$$

Since the marginal tax rate depends on income, it will depend on hours worked (and $\epsilon)$. We proceed by calculating the virtual budget constraints associated with each marginal tax rate, ignoring at first any billing ceilings. For example, let $\overline{h_{s, 1}}$ be the maximum number of hours a physician can work and still be in the lowest income-tax bracket, taxed at $\tau_{1}$. Then, for $h_{s}>\overline{h_{s}, 1}$, we solve for virtual income, $\overline{B_{2}}$, that equates

$$
\begin{aligned}
\bar{B}_{2}+\left(1-\tau_{2}\right) w \bar{h}_{s, 1}^{\delta} \epsilon & =\left(1-\tau_{1}\right) w \bar{h}_{s, 1}^{\delta} \epsilon \\
\Leftrightarrow \bar{B}_{2} & =\left(\tau_{2}-\tau_{1}\right) w \bar{h}_{s, 1}^{\delta} \epsilon \\
& =\left(\tau_{2}-\tau_{1}\right) \bar{E}_{w, 1} .
\end{aligned}
$$

This generalizes easily to find the virtual income that equates earnings at between the $j^{\text {th }}$ and $j-1^{\text {th }}$ income-tax bracket:

$$
\bar{B}_{j}=\sum_{k=1}^{j-1}\left(\tau_{i+1}-\tau_{i}\right) \bar{E}_{w, i} .
$$

Billing ceilings are easily added by noting that physicians are taxed on income received. Once the billing ceiling is attained, after tax earnings become

$$
\left(1-\tau_{j}\right)\left(1-\tau_{c}\right) w h^{\delta} \epsilon
$$

where $\tau_{j}$ is the marginal tax rate. To calculate the optimal hours in this context we proceed piecewise throughout the composite budget constraint following Hausman (1979) and Moffitt (1990). Given the kink points, $\bar{h}_{s, c}$ depend on $\epsilon$, the program must be solved for each draw of $\epsilon$, for each individual. 


\subsection{Estimation Results}

The estimates are given in Table 3 . The case of physicians providing 2 services is given in the first column. The estimated value of $\delta$ is equal to 0.625 and the value of $\rho$ is equal to -0.139 . The case of physicians providing 3 services is given in the second column. The value of $\delta$ is equal to 0.649 and the value of $\rho$ is equal to -.112 . The results for physicians providing 4 services are given in the third column 24 The value of $\delta$ is 0.684 and the value of $\rho$ is -0.174 .

\subsection{Model Fit}

The model fit is presented for each set of physicians in Figures 2-4. In each case we concentrate on the predicted and observed aggregate first moments of log earnings and log hours. Predicted moments are given by the hollow symbols and observed moments, the solid symbols. While a statistical test, such as one based on the value of the overidentification statistic, is technically rejected by the data, it is clear that the model replicates the observed moments quite well. However, in all cases there is a tendency to overestimate both hours and earnings in year 4 .

\subsubsection{Incentive Effects}

Estimation of the structural model allows us to provide a complete characterization of the reaction of physicians to monetary incentives. We use our estimates to calculate the income and substitution effects of price changes on total hours providing services, $h_{s}$ and services supplied. These are presented in Tables 4, 5, 6, and 7, for the cases of physicians providing two, three and four services, respectively. In each case, we report the overall effect of the price change, along with its income and substitution effect. In table 4 the different rows present the induced changes in total clinical hours providing services among physicians providing services 1 and 2, total clinical hours providing services among physicians providing services 1 and 3, the elasticity of service 1 among physicians providing services 1 and 2 , the elasticity of service 1 among physicians providing services 1 and 3 , the elasticity of service 2 , and the elasticity of service 3 . The other tables follow the same format. The tables present the elasticity with respect to the relevant price (given

\footnotetext{
${ }^{24}$ These estimates are based on a restricted sample, including only physicians providing services $1,2,4$ and 5. There were only 116 physicians providing services $1,2,3$ and 4 , which led to numerical problems and a non-positive definite variance-covariance matrix of the moments in the second stage estimation process.
} 
Table 3: Estimation Results

\begin{tabular}{|c|c|c|c|}
\hline Parameter & 2 services & 3 services & 4 services \\
\hline$\rho$ & $\begin{array}{l}-0.139 * * * \\
(0.013)\end{array}$ & $\begin{array}{c}-0.112^{* * *} \\
(0.009)\end{array}$ & $\begin{array}{l}-0.174^{* * *} \\
(0.013)\end{array}$ \\
\hline$\delta$ & $\begin{array}{l}0.625^{* * *} \\
(0.018)\end{array}$ & $\begin{array}{l}0.649 * * * \\
(0.011)\end{array}$ & $\begin{array}{l}0.684^{* * *} \\
(0.013)\end{array}$ \\
\hline$\tilde{b}_{1}$ & $\begin{array}{l}4.172^{* * *} \\
(0.262)\end{array}$ & $\begin{array}{l}8.614^{* * *} \\
(0.390)\end{array}$ & $\begin{array}{l}2.914^{* * *} \\
(0.103)\end{array}$ \\
\hline$\tilde{b}_{2}$ & $\begin{array}{l}7.897^{* * *} \\
(0.590)\end{array}$ & $\begin{array}{l}9.046^{* * *} \\
(0.568)\end{array}$ & $\begin{array}{l}3.931^{* * *} \\
(0.160)\end{array}$ \\
\hline$\tilde{b}_{3}$ & $\begin{array}{l}3.449^{* * *} \\
(0.211)\end{array}$ & $\begin{array}{l}11.205^{* * *} \\
(0.579)\end{array}$ & - \\
\hline$\tilde{b}_{4}$ & & & $\begin{array}{l}3.777^{* * *} \\
(0.169)\end{array}$ \\
\hline$\tilde{b}_{5}$ & & $\begin{array}{c}3.674^{* * *} \\
(0.160)\end{array}$ & $\begin{array}{c}3.239^{* * *} \\
(0.121)\end{array}$ \\
\hline$\tilde{b}_{6}$ & & $\begin{array}{l}1.750^{* * *} \\
(0.075)\end{array}$ & \\
\hline$\tilde{b}_{1,3}$ & $\begin{array}{c}-2.361^{* * *} \\
(0.249)\end{array}$ & & \\
\hline$\tilde{b}_{1,125}$ & & $\begin{array}{c}-2.289^{* * *} \\
(0.398)\end{array}$ & \\
\hline$\tilde{b}_{1,126}$ & & $\begin{array}{l}-0.645^{*} \\
(0.370)\end{array}$ & \\
\hline$\tilde{b}_{2,125}$ & & $\begin{array}{c}4.555^{* * *} \\
(0.621)\end{array}$ & \\
\hline$\tilde{b}_{2,126}$ & & $\begin{array}{c}-6.692^{* * *} \\
(0.557)\end{array}$ & \\
\hline$\sigma$ & $\begin{array}{l}0.762^{* * *} \\
(0.026)\end{array}$ & $\begin{array}{l}0.436^{* * *} \\
(0.013)\end{array}$ & $\begin{array}{l}0.339^{* * *} \\
(0.017)\end{array}$ \\
\hline Observations & 1,300 & 1,283 & 472 \\
\hline
\end{tabular}

Standard errors in parentheses

$* * *, * *$, denote signficance at $1 \%$ and $5 \%$, respectively. 
Figure 2

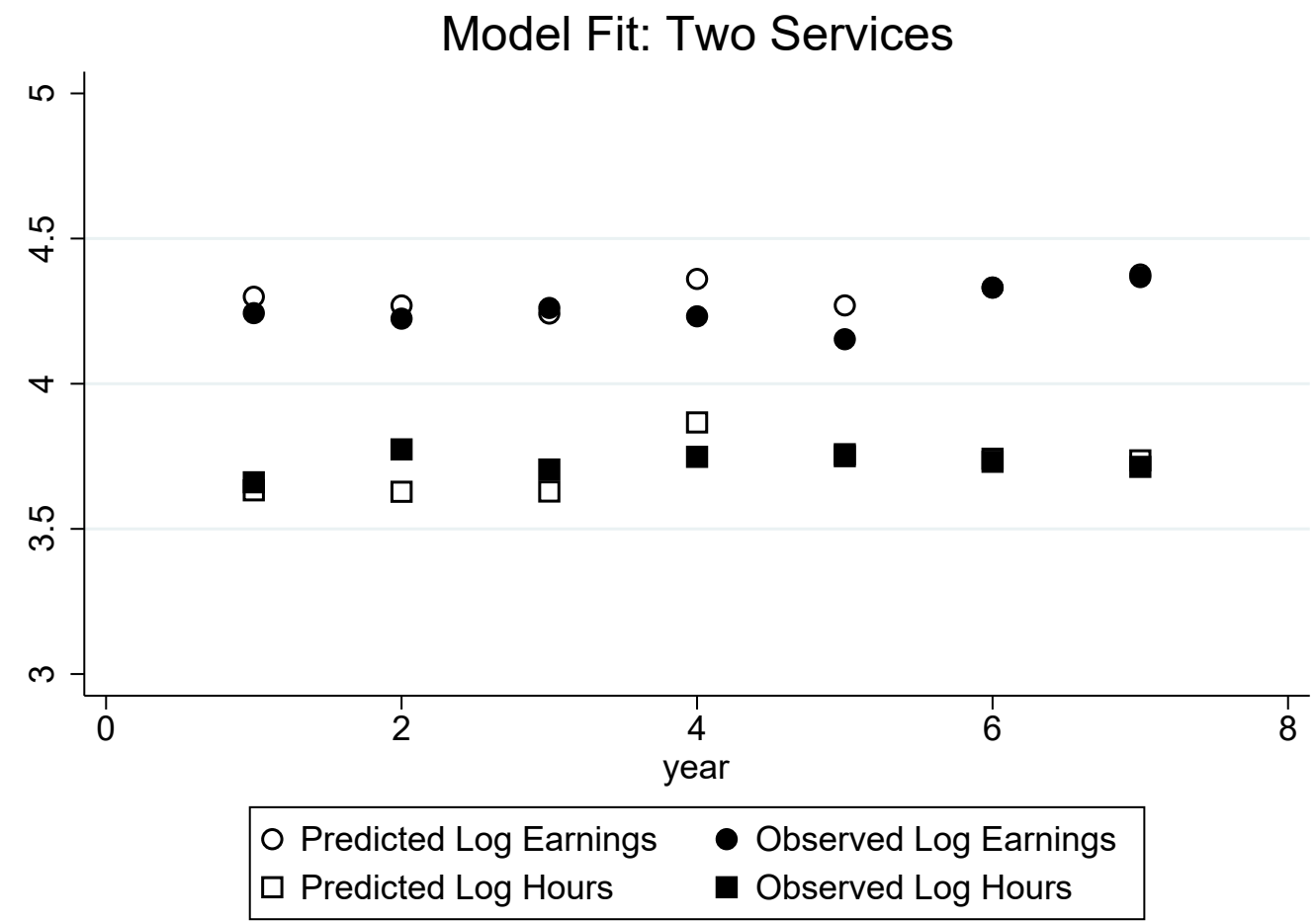

at the top of each column), as well as the $95 \%$ confidence interval, based on 99 draws of the parameter vector from its asymptotic normal distribution.

The results vary across specifications, but general patterns are evident. All specifications display negative income effects, for both total hours devoted to services and specific services. Given an increase in outside income, physicians reduce their supply of clinical services and their supply of services. The price changes induce positive own-price effects on services, suggesting that the substitution effects outweigh the income effects, and negative cross-price effects. The effects are all significant at the $5 \%$ level as the confidence intervals do not cover zero. The effects of price increases on clinical hours is negative. For example, from Table 4 , an increase in the price of service 1 induces physicians who provide services 1 and 2 to reduce their total clinical hours (the elasticity is -.041). Yet, they increase their supply of service 1 (the elasticity is 1.409) as a larger proportion of the hours supplied are allocated to service 1 to take advantage of the higher price. The presence of 
Figure 3

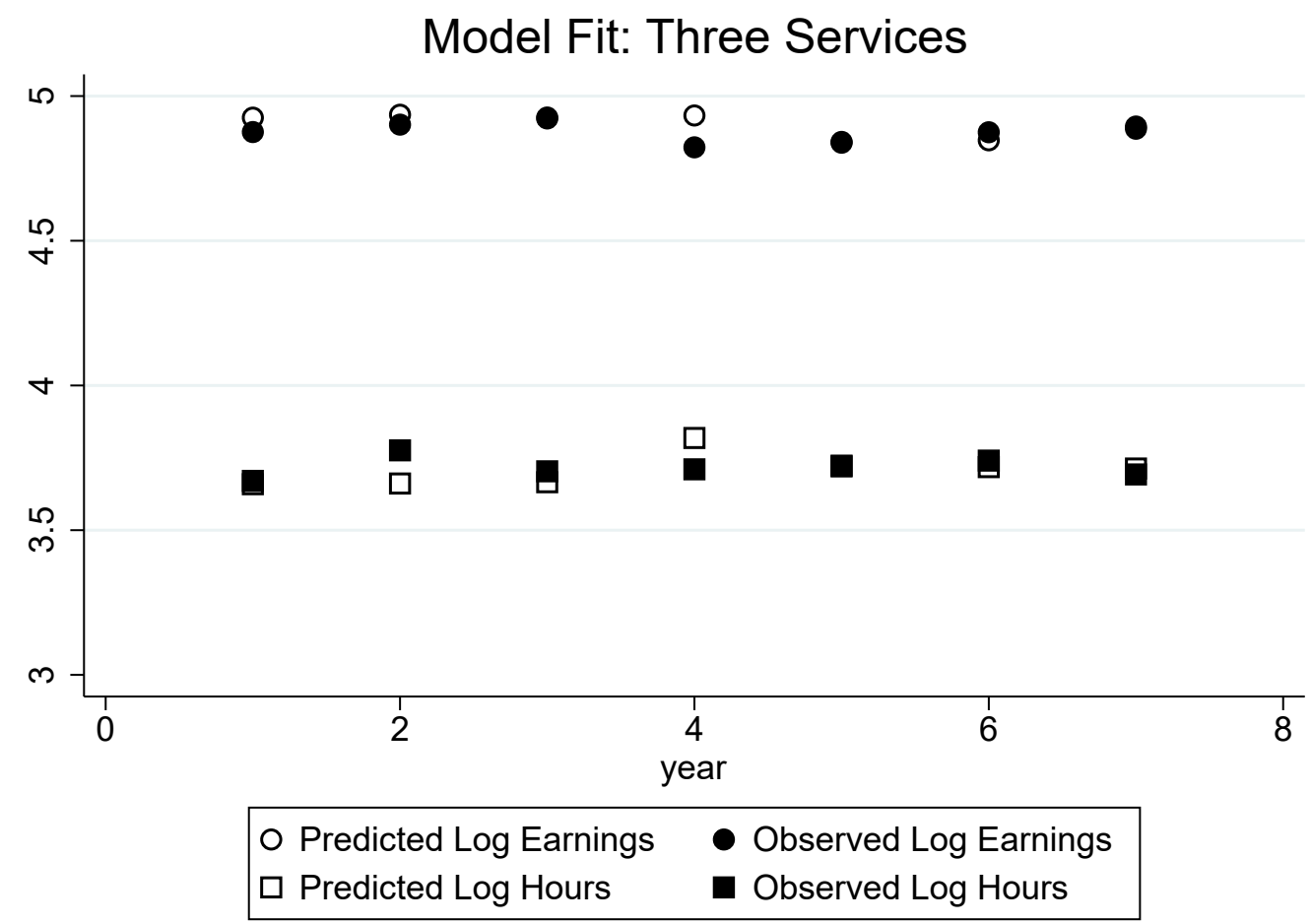

positive and non-symmetric cross-price substitution effects are also noted (between services 1 and 3, for example) confirming the possibility suggested by (16). 
Figure 4

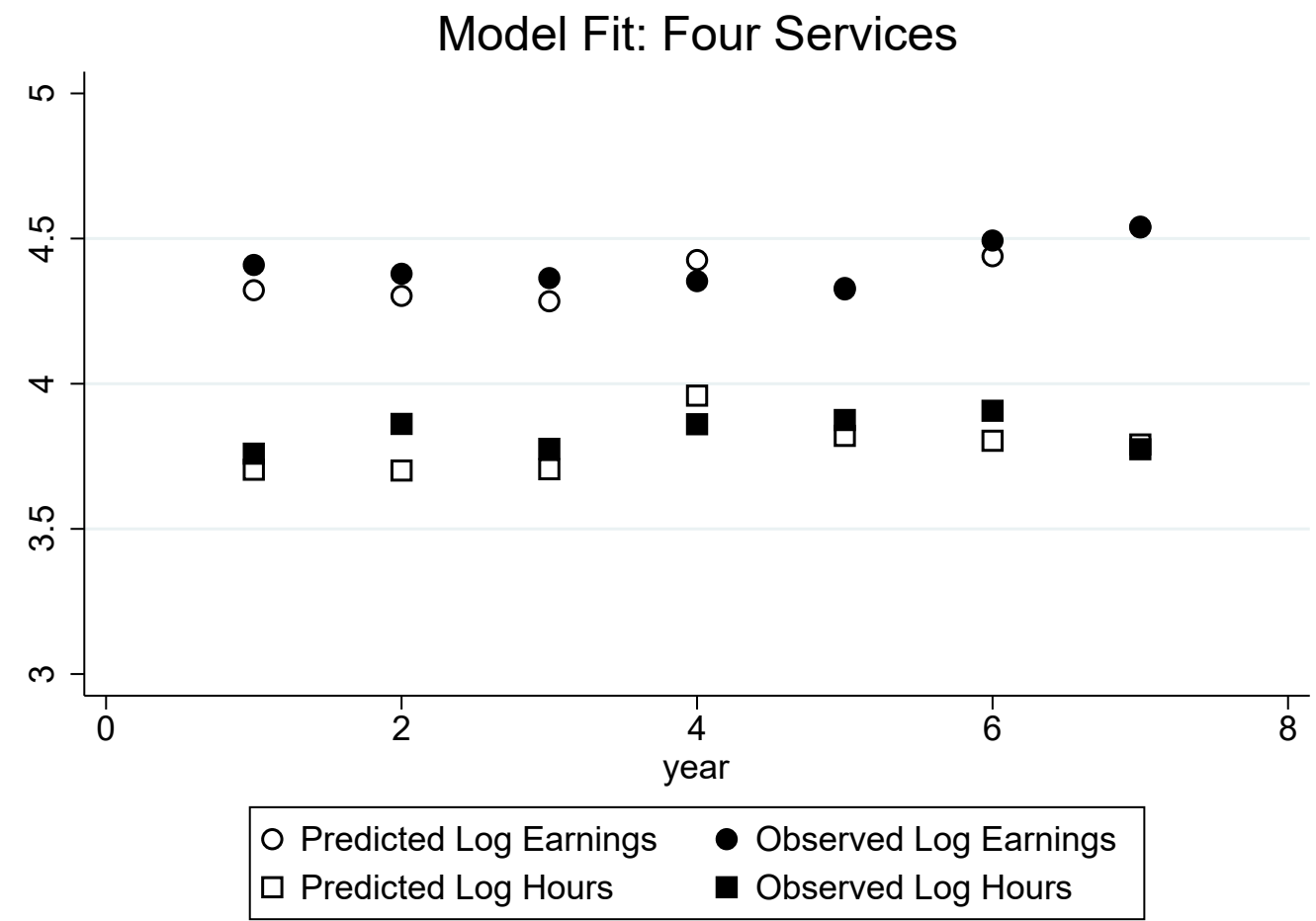

\section{Policy simulations}

Estimation of the structural model allows us to predict how physicians would respond to policy changes by the government. As the data are historic, we can take advantage of past price increases enacted by the government and compare the model's predictions to reported actual responses . Between 2007 and 2011, the Quebec government increased the prices paid for physician services by 30\%. Contandriopoulos and Perroux (2013) presented aggregate evidence that this increase led physicians to reduce their supply of services.

We calculated (18) at the estimated parameter values. The results are presented in Table 8 For all cases, hours worked and the volume of all services are predicted to decrease. The elasticities are all of a similar order of magnitude: between 0.074 and 0.107 . Multiplying by 30 and by the relevant estimate of $\delta$ gives estimates of the percent service response 
Table 4: Elasticities: 2 Services

\begin{tabular}{|c|c|c|c|}
\hline & $P_{1}$ & $P_{2}$ & $P_{3}$ \\
\hline Weekly clinical hours $\left(h_{s 12}\right)$ & -.041 & -.041 & - \\
95\% Confidence Interval & {$[-.048,-.035]$} & {$[-.048,-.035]$} & - \\
Income Effect & -.339 & -.338 & - \\
Substitution Effect & .297 & .297 & - \\
\hline \hline Weekly clinical hours $\left(h_{s 13}\right)$ & -.096 & - & -.096 \\
95\% Confidence Interval & {$[-.111,-.079]$} & - & {$[-.110,-.079]$} \\
Income Effect & -.789 & - & -.787 \\
Substitution Effect & .693 & - & .691 \\
\hline \hline$A_{1,2}$ & 1.409 & -1.461 & - \\
95\% Confidence Interval & {$[1.252,1.603]$} & {$[-1.655,-1.310]$} & - \\
Income Effect & -.212 & -.211 & - \\
Substitution Effect & 1.622 & -1.249 & - \\
\hline$A_{1,3}$ & 1.387 & - & -1.507 \\
95\% Confidence Interval & {$[1.234,1.604]$} & - & {$[-1.722,-1.351]$} \\
Income Effect & -.494 & - & -.493 \\
Substitution Effect & 1.881 & - & -1.014 \\
\hline$A_{2}$ & -.276 & .225 & - \\
\hline 95\% Confidence Interval & {$[-.330,-.235]$} & {$[.182, .280]$} & - \\
Income Effect & -.212 & -.212 & - \\
Substitution Effect & -.064 & .436 & - \\
\hline$A_{3}$ & -.298 & - & .179 \\
95\% Confidence Interval & {$[-.342,-.261]$} & - & {$[.138, .224]$} \\
Income Effect & -.494 & - & -.493 \\
Substitution Effect & .196 & - & .672 \\
\hline \hline & & & \\
\hline & & - & - \\
\hline
\end{tabular}

to the $30 \%$ increase in all prices. This gives $-1.73 \%,-1.44 \%$ and $-2.20 \%$ for the cases of physicians providing 2, 3 and 4 services, respectively. These results contrast with those in which the price of single service is increased (see Tables 4,6 and 7), which generally give large and positive own-price effects. The difference is due to the lack of a substitution effect on any specific service. A broad-based price increase does not change relative prices, but only affects the return to an hour's work (the wage index). It therefore introduces an income and substitution effect on hours devoted to services, which are then distributed 
Table 5: Hours Elasticities: 3 Services

\begin{tabular}{|c|c|c|c|c|c|}
\hline & $P_{1}$ & $P_{2}$ & $P_{3}$ & $P_{4}$ & $P_{5}$ \\
\hline Weekly clinical hours $\left(h_{s 123}\right)$ & -0.018 & -0.018 & -0.018 & & \\
95\% Confidence Interval & {$[-0.020,-0.016]$} & {$[-0.020,-0.016]$} & {$[-0.020,-0.016]$} & & \\
Income Effect & -0.178 & -0.178 & -0.178 & & \\
Substitution Effect & 0.161 & 0.160 & 0.160 & & \\
\hline \hline Weekly clinical hours $\left(h_{s 124}\right)$ & -0.018 & -0.018 & & -0.018 & \\
95\% Confidence Interval & {$[-0.020,-0.016]$} & {$[-0.020,-0.016]$} & & {$[-.020,-.016]$} & -0.181 \\
Income Effect & -0.181 & -0.181 & & 0.163 & \\
Substitution Effect & 0.163 & 0.163 & & & -0.033 \\
\hline \hline Weekly clinical hours $\left(h_{s 125}\right)$ & -0.033 & -0.032 & & & -0.328 \\
95\% Confidence Interval & {$[-0.037,-0.029]$} & {$[-0.037,-0.029]$} & & & 0.296 \\
Income Effect & -0.328 & -0.328 & & \\
Substitution Effect & 0.295 & 0.295 & & & \\
\hline \hline
\end{tabular}

over all services 25

\section{Discussion and Conclusion}

We have developed and estimated a structural labour supply model that incorporates the production of medical services and the allocation of hours across services (multitasking) into the standard consumption/leisure trade-off. The equilibrium of the model gives rise to a wage index for clinical hours when those hours are optimally distributed across different medical services. The wage index captures physicians' ability to substitute between services and hence contains economically relevant information on physician response to incentives. Our model also provides an implicit function defining optimal clinical hours worked. We have applied our model to analyze the response of fee-for-service physicians to changes in fees using data from the Province of Quebec.

Our results suggest that physicians react to incentives in predictable ways. While income effects are present, and tend to reduce hours worked and services provided, substitution effects outweigh them when the price of a single service is changed. Changing

\footnotetext{
${ }^{25}$ This result is also consistent with a " target income hypothesis" Kantarevic, Kralj, and Weinkauf (2008); Rizzo and Blumenthal (1994); McGuire and Pauly (1991).
} 
Table 6: Service Elasticities: 3 Services

\begin{tabular}{|c|c|c|c|c|c|}
\hline & $P_{1}$ & $P_{2}$ & $P_{3}$ & $P_{4}$ & $P_{5}$ \\
\hline $\begin{array}{c}A_{1,123} \\
\text { 95\% Confidence Interval } \\
\text { Income Effect } \\
\text { Substitution Effect }\end{array}$ & $\begin{array}{c}1.438 \\
{[1.347,1.555]} \\
-0.116 \\
1.554\end{array}$ & $\begin{array}{c}-0.502 \\
{[-0.578,-0.443]} \\
-0.116 \\
-0.387\end{array}$ & $\begin{array}{c}-0.971 \\
{[-1.048,-0.899]} \\
-0.116 \\
-0.855\end{array}$ & & \\
\hline $\begin{array}{c}A_{1,124} \\
\text { 95\% Confidence Interval } \\
\text { Income Effect } \\
\text { Substitution Effect }\end{array}$ & $\begin{array}{c}1.668 \\
{[1.569,1.819]} \\
-0.118 \\
1.786\end{array}$ & $\begin{array}{c}-1.644 \\
{[-1.780,-1.545]} \\
-0.118 \\
-1.527\end{array}$ & & $\begin{array}{c}-0.058 \\
{[-0.070,-0.049]} \\
-0.118 \\
0.059\end{array}$ & \\
\hline $\begin{array}{c}A_{1,125} \\
95 \% \text { Confidence Interval } \\
\text { Income Effect } \\
\text { Substitution Effect }\end{array}$ & $\begin{array}{c}0.073 \\
{[0.063,0.085]} \\
-0.213 \\
0.286\end{array}$ & $\begin{array}{c}-0.079 \\
{[-0.087,-0.072]} \\
-0.212 \\
0.134\end{array}$ & & & $\begin{array}{c}-0.057 \\
{[-0.063,-0.051]} \\
-0.213 \\
0.156\end{array}$ \\
\hline $\begin{array}{c}A_{2,123} \\
95 \% \text { Confidence Interval } \\
\text { Income Effect } \\
\text { Substitution Effect }\end{array}$ & $\begin{array}{c}-0.419 \\
{[-0.495,-0.359]} \\
-0.116 \\
-0.303\end{array}$ & $\begin{array}{c}1.355 \\
{[1.241,1.493]} \\
-0.116 \\
1.471\end{array}$ & $\begin{array}{c}-0.971 \\
{[-1.048,-0.899]} \\
-0.116 \\
-0.855\end{array}$ & & \\
\hline $\begin{array}{c}A_{2,124} \\
95 \% \text { Confidence Interval } \\
\text { Income Effect } \\
\text { Substitution Effect }\end{array}$ & $\begin{array}{c}-0.190 \\
{[-0.212,-0.170]} \\
-0.118 \\
-0.072\end{array}$ & $\begin{array}{c}0.213 \\
{[0.187,0.245]} \\
-0.118 \\
0.321 \\
\end{array}$ & & $\begin{array}{c}-0.058 \\
{[-0.070,-0.049]} \\
-0.118 \\
0.059\end{array}$ & \\
\hline $\begin{array}{c}A_{2,125} \\
95 \% \text { Confidence Interval } \\
\text { Income Effect } \\
\text { Substitution Effect }\end{array}$ & $\begin{array}{c}-1.785 \\
{[-1.926,-1.669]} \\
-0.213 \\
-1.571\end{array}$ & $\begin{array}{c}1.778 \\
{[1.664,1.922]} \\
-0.213 \\
1.991\end{array}$ & & & $\begin{array}{c}-0.057 \\
{[-0.063,-0.051]} \\
-0.213 \\
0.156\end{array}$ \\
\hline $\begin{array}{c}A_{3} \\
\text { 95\% Confidence Interval } \\
\text { Income Effect } \\
\text { Substitution Effect }\end{array}$ & $\begin{array}{c}-0.419 \\
{[-0.495,-0.359]} \\
-0.116 \\
-0.303\end{array}$ & $\begin{array}{c}-.502 \\
{[-0.578,-0.443]} \\
-0.116 \\
-0.387\end{array}$ & $\begin{array}{c}0.887 \\
{[0.823,0.979]} \\
-0.116 \\
1.003\end{array}$ & & \\
\hline $\begin{array}{c}A_{4} \\
\text { 95\% Confidence Interval } \\
\text { Income Effect } \\
\text { Substitution Effect } \\
\end{array}$ & $\begin{array}{c}-0.190 \\
{[-0.212,-0.170]} \\
-0.118 \\
-0.072\end{array}$ & $\begin{array}{c}-1.644 \\
{[-1.780,-1.545]} \\
-0.118 \\
-1.527\end{array}$ & & $\begin{array}{c}1.799 \\
{[1.691,1.938]} \\
-0.118 \\
1.917\end{array}$ & \\
\hline $\begin{array}{c}A_{5} \\
\text { 95\% Confidence Interval } \\
\text { Income Effect } \\
\text { Substitution Effect }\end{array}$ & $\begin{array}{c}-1.785 \\
{[-1.926,-1.669]} \\
-0.213 \\
-1.572\end{array}$ & $\begin{array}{c}-0.079 \\
{[-0.087,-0.072]} \\
-0.213 \\
0.134\end{array}$ & & & $\begin{array}{c}1.801 \\
{[1.682,1.948]} \\
-0.213 \\
2.014\end{array}$ \\
\hline
\end{tabular}


Table 7: Hours Elasticities: 4 Services

\begin{tabular}{|c|c|c|c|c|}
\hline & $P_{1}$ & $P_{2}$ & $P_{3}$ & $P_{5}$ \\
\hline Weekly clinical hours $\left(h_{s 1235}\right)$ & -0.060 & -0.060 & -0.060 & -0.060 \\
$95 \%$ Confidence Interval & {$[-0.066,-0.052]$} & {$[-0.066,-0.052]$} & {$[-0.066,-0.052]$} & {$[-0.066,-0.052]$} \\
Income Effect & -0.405 & -0.405 & -0.406 & -0.405 \\
Substitution Effect & 0.345 & 0.346 & 0.346 & 0.345 \\
\hline \hline$A_{1,1235}$ & 1.870 & -0.774 & -0.763 & -0.497 \\
$95 \%$ Confidence Interval & {$[1.711,2.076]$} & {$[-0.863,-0.706]$} & {$[-0.833,-0.699]$} & {$[-0.555,-0.458]$} \\
Income Effect & -0.277 & -0.279 & -0.278 & -0.278 \\
Substitution Effect & 2.148 & -0.496 & -0.485 & -0.220 \\
\hline$A_{2,1235}$ & -0.312 & 1.409 & -0.763 & -0.497 \\
$95 \%$ Confidence Interval & {$[-0.349,-0.280]$} & {$[1.285,1.566]$} & {$[-0.833,-0.699]$} & {$[-0.555,-0.458]$} \\
Income Effect & -0.277 & -0.278 & -0.278 & -0.278 \\
Substitution Effect & -0.035 & 1.687 & -0.485 & -0.220 \\
\hline$A_{3,1235}$ & -0.312 & -0.774 & 1.419 & -0.530 \\
95\% Confidence Interval & {$[-0.349,-0.280]$} & {$[-0.863,-0.706]$} & {$[1.283,1.577]$} & {$[-0.588,-0.485]$} \\
Income Effect & -0.277 & -0.278 & -0.278 & -0.310 \\
Substitution Effect & -0.035 & -0.496 & 1.697 & -0.220 \\
\hline$A_{5}$ & -0.312 & -0.774 & -0.763 & 1.685 \\
95\% Confidence Interval & {$[-0.349,-0.280]$} & {$[-0.863,-0.706]$} & {$[-0.833,-0.699]$} & {$[1.548,1.877]$} \\
Income Effect & -0.277 & -0.278 & -0.278 & -0.278 \\
Substitution Effect & -0.035 & -0.496 & -0.485 & 1.963 \\
\hline \hline
\end{tabular}

many prices in unison however, introduces a large income effect which reduces the supply of services. These results have policy implications for the provision of heath services. Governments (or other health care providers) who are faced with increased demand for particular medical services (and accompanying waiting times) can use price controls to increase the supply of those services. In general, our results highlight the fact that increasing individual fees will lead to a significant increase in the supply of those services. We note that, while our approach to modelling behaviour differs, our results pointing to the importance of the income effect are qualitatively consistent with those of Fortin, Jacquemet, and Shearer (2017) who used flexible functional forms to approximate the utility function and discretized the choice set over practice variables.

The simplicity of our model is one of its attractive features. It is parsimonious, leading to a relatively small number of estimated parameters and easily interpretable comparative 
Table 8: Policy Analysis

\begin{tabular}{||c|c|c|c||}
\hline Variable & Two Services & Three Services & Four Services \\
\hline$h s_{1,2}$ & -0.092 & & \\
95\% Confidence Interval & {$[-0.103,-0.079]$} & & \\
Income Effect & -0.753 & & \\
Substitution Effect & 0.661 & & \\
\hline$h s_{1,3}$ & -0.094 & & \\
$95 \%$ C. I. & {$[-0.106,-0.080]$} & & \\
Income Effect & -0.776 & & \\
Substitution Effect & 0.682 & & \\
\hline$h s_{1,2,3}$ & & -0.074 & \\
$95 \%$ C. I. & & {$[-0.084,-0.066]$} & \\
Income Effect & & -0.746 & \\
Substitution Effect & & 0.672 & \\
\hline$h s_{1,2,4}$ & & -0.074 & \\
$95 \%$ C. I. & & $-.084,-.067]$ & \\
Income Effect & & -0.747 & \\
Substitution Effect & & -0.672 & \\
\hline$h s_{1,2,5}$ & & -0.076 & \\
$95 \%$ C. I. & & -0.760 & \\
Income Effect & & 0.684 & -0.107 \\
Substitution Effect & & $-0.098]$ \\
\hline$h s_{1,2,4,5}$ & & - & 0.618 \\
\hline $95 \%$ C. I. & & & \\
Income Effect & & & \\
Substitution Effect & & & \\
\hline \hline
\end{tabular}


statics. Yet it is powerful enough to predict physician behaviour, capturing both income and substitution effects. Nevertheless, the model is limited and it can be extended in various ways to allow for a richer analysis of physician behaviour.

While our sample only includes physicians who are present before and after the price changes, we have ignored participation in physician's labour-supply decision. Incorporating participation decisions into our model shifts attention to moments that are conditional on working. To the extent that participation decisions depend on potential productivity, this can affect the parameter estimates. We have also ignored observable heterogeneity among physicians. A natural way to incorporate this into the model is through the weighting parameter introduced into the preferences on hours worked. Heterogeneity also raises questions of possible instruments for hours worked and the relative benefits of limited-information estimation that conditions on hours worked. We leave an investigation of the importance of these issues for future work.

Part of the model's parsimony is due to the aggregation of services and the assumption of common shocks. Eliminating aggregation and introducing service-specific shocks would be an interesting extension, but would increase the numerical intensity of solving and estimating the model. Doing so would allow the incorporation of demand and technology shocks as determinants of the variation in observed services. It would also allow consideration of agency questions as service-specific shocks might be observed uniquely by the physician. This would allow the measurement of the extent of asymmetric information in the medical profession.

We have also assumed that the fee changes are exogenous and independent of physician productivity. This would be violated if, for example, the government changed fees in response to technological changes that reduced the time needed to perform certain services. While modelling the fee setting behaviour of the government in such situations poses no special problems from an econometric point of view - see Paarsch and Shearer (1999) for one possible approach - doing so imposes a certain level of economic rationality on the part of the government which may or may not be present. Developing models that allow for the detection of rational price setting on the part of the government is also worthy of future research.

Physician productivity may change over time, due, for example, to learning by doing. Extending the model in such a direction gives rise to dynamic issues of labour supply and health-care policy. For example, the government may want to induce young physicians to spend more time in the labour market in order to increase future productivity. See Somé (2016) for a discussion of these issues. 
Finally, we have concentrated on evaluating the volume-increase response of physicians to fee increases. It would be interesting to extend this model to account for the quality of services provided. Estimating a model that takes account of the quality of care will require data on the health outcomes of patients and following patients through time. 


\section{References}

Allin, S., M. BAKer, M. Isabelle, And M. Stabile (2015): "Physician Incentives and the Rise in C-Sections: Evidence from Canada," NBER Working Papers, Working Paper 21022.

Baltagi, B. H., E. BratberG, AND T. H. Holmas (2005): “A panel data study of physicians' labor supply: the case of Norway," Health Economics, 14(10), 1035-1045.

BLOMQUIST, N. S. (1989): “Comparative Statics for Utility Maximization Models with Nonlinear Budget Constraints," International Economic Review, 30(2), 275-296.

BLUNDElL, R., AND T. MACURDy (1999): “Labor Supply: a Review of Alternative Approaches," in Handbook of Labor Economics, Volume 3A, ed. by O. C. Ashenfelter, and D. Card. Elsevier.

Contandriopoulos, D., AND M. Perroux (2013): "Fee Increases and Target Income Hypothesis: Data from Quebec on Physicians' Compensation and Service Volumes," Healthcare Policy, 9, 30-35.

Deaton, A., AND J. Muellbauer (1980): Economics and Consumer Behavior. Cambridge University Press.

Evans, R. G. (1974): "Supplier-Induced Demand: Some Empirical Evidence and Implication," in The Economics of Health and Medical Care, ed. by M. Perlman. Macmillan.

Feldstein, M. S. (1970): “The Rising Price of Physicians' Services," The Review of Economics and Statistics, 52(2), 121-33.

Fortin, B., N. Jacquemet, AND B. SheARer (2017): “Labour Supply and Service Intensity: Theory and Evidence on Physicians," mimeo.

GRUber, J., AND M. OWINGS (1996): "Physician Financial Incentives and Cesarean Section Delivery," The RAND Journal of Economics, 27(1), 99-123.

HaUsman, J. A. (1979): “The econometrics of labor supply on convex budget sets," Economics Letters, 3(2), 171-174.

Holmstrom, B., AND P. Milgrom (1991): “Multitask Principal-Agent Analyses: Incentive Contracts, Asset Ownership, and Job Design," Journal of Law, Economics \& Organization, 7, 24-52.

HURLEY, J., AND R. LABELlE (1995): “Relative fees and the utilization of physicians' services in Canada," Health Economics, 4(6), 419-438.

Kalman, P. J., AND M. D. Intriligator (1973): “Generalized Comparative Statics with Applications to Consumer Theory and ProducerTheory," International Economic Review, 14(2), 473-486. 
Kantarevic, J., B. Kralj, And D. Weinkauf (2008): “Income effects and physician labour supply: evidence from the threshold system in Ontario," Canadian Journal of Economics, 41(4), 1262-1284.

MCGuire, T. G., AND M. V. PAuly (1991): "Physician response to fee changes with multiple payers," Journal of Health Economics, 10(4), 385-410.

MilligAN, K. (2016): Canadian Tax and Credit Simulator. Database, software and documentation, Version 2016-2.

MoffitT, R. (1990): “The Econometrics of Kinked Budget Constraints," The Journal of Economic Perspectives, 4(2), 119-139.

PAARSCH, H. J., AND B. SHEARER (1999): “The Response of Worker Effort to Piece Rates: Evidence from the British Columbia Tree-Planting Industry," The Journal of Human Resources, 34(4), pp. 643-667.

Rizzo, J. A., AND D. Blumenthal (1994): “Physician labor supply: Do income effects matter?," Journal of Health Economics, 13(4), 433-453.

SlOAN, F. A. (1975): "Physician supply behavior in the short run," Industrial and Labor Relations Review, 28(4), 549-569.

SOMÉ, H. (2016): "Modelling and Estimating Models of Physician Labour Supply and Productivity," Phd. Thesis, Laval University.

Stern, N. (1986): "On the Specification of Labour Supply Functions," in Unemployment, Search and Labour Supply, ed. by R. Blundell, and I. Walker. Cambridge University Press.

STERN, N. H. (1976): “On the Specification of Models of Optimum Income Taxation," Journal of Public Economics, 6, 123-62.

ZABALZA, A. (1983): "The CES utility function, non-linear budget constraints and labour supply. Results on female participation and hours," Economic Journal, 93, 312-330. 


\section{Appendix A1: Elasticities}

Let

$$
F\left(h_{s}, \alpha_{1}, \alpha_{2}, \ldots \alpha_{J}, y, \epsilon\right)=\omega \delta h_{s}^{\delta-1} \epsilon\left(\omega h_{s}^{\delta} \epsilon+y\right)^{\rho-1}-2^{1-\rho}\left(T-h_{s}\right)^{\rho-1},
$$

where

$$
\omega=\left[\sum_{J=1}^{I}\left(\alpha_{j} b_{j}\right)^{\frac{1}{1-\delta}}\right]^{(1-\delta)}
$$

and note that optimal $h_{s}^{*}$ solves

$$
F\left(h_{s}^{*}, \alpha_{1}, \alpha_{2}, \ldots \alpha_{J}, y, \epsilon\right)=0,
$$

with the second-order condition

$$
F_{h_{s}} \equiv \frac{\partial F\left(h_{s}^{*}, \alpha_{1}, \alpha_{2}, \ldots \alpha_{J}, y, \epsilon\right)}{\partial h_{s}}<0 .
$$

By the implicit function theorem, we can write

$$
h_{s}^{*}=\psi\left(\alpha_{1}, \alpha_{2}, \ldots \alpha_{J}, y, \epsilon\right) .
$$

Furthermore,

$$
\frac{d h_{s}^{*}}{d \alpha_{j}}=-\frac{\frac{\partial F}{\partial \alpha_{j}}}{\frac{\partial F}{\partial h_{s}}}
$$

and

$$
\frac{d h_{s}^{*}}{d y}=-\frac{\frac{\partial F}{\partial y}}{\frac{\partial F}{\partial h_{s}}} .
$$


We use the following notation:

(i) $M=w h_{s}^{\delta} \epsilon+y$.

(ii) $\omega=\left[\sum_{j=1}^{J}\left(\alpha_{j} b_{j}\right)^{\frac{1}{1-\delta}} \cdot\right]^{(1-\delta)}$

(iii) $P_{j}=\left(\alpha_{j} b_{j}\right)^{\frac{1}{1-\delta}}$.

We note

$$
\frac{\partial w}{\partial \alpha_{j}}=b_{j}\left(\frac{P_{j}}{\sum_{i} P_{i}}\right)^{\delta}>0 .
$$

We will use the following results which rely on the parameters satisfying the second-order condition, i.e., $\rho<1$ and $\delta \in(0,1)$.

$$
\begin{aligned}
F_{h_{s}} & =w \epsilon \delta(\delta-1) h_{s}^{\delta-2} M^{\rho-1}+(\rho-1)\left(w \delta h_{s}^{\delta-1} \epsilon\right)^{2} M^{\rho-2}+2^{1-\rho}(\rho-1)\left(T-h_{s}\right)^{\rho-2}<0, \\
F_{y} & =(\rho-1) w \delta h_{s}^{\delta-1} \epsilon M^{\rho-2}<0 \\
F_{\alpha_{j}} & =\frac{\partial w}{\partial \alpha_{j}} h_{s}^{\delta-1} \epsilon\left[\delta M^{\rho-1}+h_{s} F_{y}\right] \geq 0 .
\end{aligned}
$$


Income elasticity, $h_{s}$

$$
\begin{aligned}
\frac{d h_{s}}{d y} & =-\frac{F_{y}}{F_{h_{s}}}=\frac{(1-\rho) \omega \delta h_{s}^{\delta-1} \epsilon M^{\rho-2}}{F_{h_{s}}}<0, \\
\eta_{h_{s}, y} & =\frac{y}{h_{s}} \frac{(1-\rho) \omega \delta h_{s}^{\delta-1} \epsilon M^{\rho-2}}{F_{h_{s}}} .
\end{aligned}
$$

Income elasticity, $h_{j}$

Recall,

$$
h_{j}=\frac{P_{j}}{\sum_{i} P_{i}} h_{s}
$$

It follows that

$$
\frac{d h_{j}}{d y}=\frac{P_{j}}{\sum_{i} P_{i}} \frac{d h_{s}}{d y}<0, \quad \text { since } \frac{d h_{s}}{d y}<0 \text { from } 39 .
$$

Using (41] we have

$$
\eta_{h_{j}, y}=\eta_{h_{s}, y}
$$

Income elasticity, $A_{j}$

Recall,

$$
A_{j}=b_{j} h_{j}^{\delta} \epsilon
$$

It follows that

$$
\frac{d A_{j}}{d y}=\delta b_{j} h_{j}^{\delta-1} \frac{d h_{j}}{d y} \epsilon<0, \quad \text { since } \frac{d h_{j}}{d y}<0 \quad \text { from } 42 \text {. }
$$

Using (43, we have the elasticity form

$$
\eta_{A_{j}, y}=\delta \eta_{h_{j}, y}=\delta \eta_{h_{s, y}}
$$




\section{Price elasticity, $h_{S}$}

$$
\begin{aligned}
\frac{d h_{s}}{d \alpha_{j}} & =-\frac{F_{\alpha_{j}}}{F_{h_{s}}} \\
& \left.=\frac{\partial w}{\partial \alpha_{j}} h_{s}^{\delta-1 \epsilon} \epsilon-\frac{\delta M^{\rho-1}}{F_{h_{s}}}-h_{s} \frac{F_{y}}{F_{h_{s}}}\right] \\
& \left.=\frac{\partial w}{\partial \alpha_{j}} h_{s}^{\delta-1 \epsilon} \epsilon-\frac{\delta M^{\rho-1}}{F_{h_{s}}}+h_{s} \frac{d h_{s}}{d y}\right], \text { from (39) } \\
& =-\frac{\partial w}{\partial \alpha_{j}} \frac{\delta h_{s}^{\delta-1} \epsilon M^{\rho-1}}{F_{h_{s}}}+h_{s}^{\delta} \epsilon \frac{\partial w}{\partial \alpha_{j}} \frac{d h_{s}}{d y} \\
& =-b_{j}\left(\frac{P_{j} h_{s}}{\sum_{i} P_{i}}\right)^{\delta} \frac{\delta \epsilon M^{\rho-1}}{h_{s} F_{h_{s}}}+b_{j}\left(\frac{P_{j} h_{s}}{\sum_{i} P_{i}}\right)^{\delta} \frac{d h_{s}}{d y} \epsilon, \quad \text { from (38) } \\
& =-b_{j} h_{j}^{\delta} \epsilon \frac{\delta M^{\rho-1}}{h_{s} F_{h_{s}}}+b_{j} h_{j}^{\delta} \epsilon \frac{d h_{s}}{d y} \\
& =-A_{j} \frac{\delta M^{\rho-1}}{h_{s} F_{h_{s}}}+A_{j} \frac{d h_{s}}{d y} .
\end{aligned}
$$

To convert to elasticity terms, multiply by $\alpha_{j} / h_{s}$. After adjusting the income effect, we get:

$$
\eta_{h_{s}, \alpha_{j}}=-\frac{\delta \alpha_{j} A_{j} M^{\rho-1}}{h_{s}^{2} V_{h_{s} h_{s}}}+\frac{\alpha_{j} A_{j}}{y} \eta_{h_{s}, y} .
$$




\section{Own-price elasticity, $h_{j}$}

Recall,

$$
h_{j}=\frac{P_{j}}{\sum_{i} P_{i}} h_{s}
$$

We then have:

$$
\frac{\partial h_{j}}{\partial \alpha_{j}}=\frac{P_{j}}{\sum_{i} P_{i}} \frac{\partial h_{s}}{\partial \alpha_{j}}+h_{s} \frac{\partial}{\partial \alpha_{j}}\left[\frac{P_{j}}{\sum_{i} P_{i}}\right]
$$

Using (45) and the fact that $\frac{\partial P_{j}}{\partial \alpha_{j}}=\frac{P_{j}}{(1-\delta) \alpha_{j}}$, we have:

$$
\begin{aligned}
\frac{\partial h_{j}}{\partial \alpha_{j}} & =\frac{P_{j}}{\sum_{i} P_{i}}\left[-A_{j} \delta \frac{M^{\rho-1}}{h_{s} F_{h_{s}}}+A_{j} \frac{\partial h_{s}}{\partial y}\right]+\frac{P_{j} \sum_{j \neq i} P_{j}}{\left(\sum_{i} P_{i}\right)^{2}} \frac{h_{s}}{\alpha_{j}(1-\delta)} \\
& =\frac{P_{j}}{\sum_{i} P_{i}}\left[-A_{j} \delta \frac{M^{\rho-1}}{h_{s} F_{h_{s}}}+A_{j} \frac{\partial h_{s}}{\partial y}\right]+\frac{h_{j}}{\alpha_{j}(1-\delta)} \frac{\sum_{j \neq i} P_{j}}{\sum_{i} P_{i}} .
\end{aligned}
$$

Using the fact that $h_{j}=\frac{P_{j}}{\sum_{i} P_{i}} h_{s}$ and rearranging gives:

$$
\frac{\partial h_{j}}{\partial \alpha_{j}} \frac{\alpha_{j}}{h_{j}}=\left[\frac{1}{(1-\delta)} \frac{\sum_{i \neq j} P_{i}}{\sum_{i} P_{i}}-\alpha_{j} A_{j} \delta \frac{M^{\rho-1}}{h_{s}^{2} F_{h_{s}}}\right]+\frac{\alpha_{j} A_{j}}{y} \frac{\partial h_{s}}{\partial y} \frac{y}{h_{s}}
$$

Own-price elasticity, $A_{j}$

$$
\begin{aligned}
A_{j} & =b_{j} h_{j}^{\delta} \epsilon \\
\frac{\partial A_{j}}{\partial \alpha_{j}} & =b_{j} h_{j}^{\delta-1} \delta \frac{\partial h_{j}}{\partial \alpha_{j}} \\
& =\frac{A_{j}}{h_{j}} \delta \frac{\partial h_{j}}{\partial \alpha_{j}} \\
& =\delta \frac{\alpha_{j}}{h_{j}} \frac{\partial h_{j}}{\partial \alpha_{j}} . \\
\eta_{A_{j}, \alpha_{j}} & =\delta \eta_{h_{j}, \alpha_{j} .}
\end{aligned}
$$




\section{Cross-price elasticity, $h_{j}$}

$$
\begin{aligned}
\frac{\partial h_{j}}{\partial \alpha_{i}} & =\frac{P_{j}}{\sum_{l} P_{l}} \frac{\partial h_{s}}{\partial \alpha_{i}}+\frac{\partial}{\partial \alpha_{i}}\left[\frac{P_{j}}{\sum_{l} P_{l}}\right] h_{s} \\
& =\frac{P_{j}}{\sum_{l} P_{l}} \frac{\partial h_{s}}{\partial \alpha_{i}}-\frac{P_{i} P_{j}}{\alpha_{i}(1-\delta)\left(\sum_{l} P_{l}\right)^{2}} h_{s} .
\end{aligned}
$$

Using (45) and the fact that $h_{j}=\frac{P_{j}}{\sum_{l} P_{l}} h_{s} \quad$ we have:

$$
\begin{aligned}
\frac{\partial h_{j}}{\partial \alpha_{i}} & =-\frac{P_{j}}{\sum_{l} P_{l}} \frac{A_{i} \delta M^{\rho-1}}{h_{s} F_{h_{s}}}+\frac{P_{j}}{\sum_{l} P_{l}} A_{i} \frac{\partial h_{s}}{\partial y}-\frac{h_{i} h_{j}}{h_{s}} \frac{1}{(1-\delta) \alpha_{i}} \\
& =-\left[\frac{h_{j}}{h_{s}^{2}} \frac{A_{i} \delta M^{\rho-1}}{F_{h_{s}}}+\frac{h_{i} h_{j}}{h_{s}} \frac{1}{(1-\delta) \alpha_{i}}\right]+\frac{P_{j}}{\sum_{l} P_{l}} A_{i} \frac{\partial h_{s}}{\partial y} .
\end{aligned}
$$

Finally, using $\quad \frac{\partial h_{j}}{\partial y}=\frac{P_{j}}{\sum_{l} P_{l}} \frac{\partial h_{s}}{\partial y}$, we have:

$$
\frac{\partial h_{j}}{\partial \alpha_{i}}=-\frac{h_{j}}{\alpha_{i}}\left[\frac{h_{i}}{h_{s}} \frac{1}{(1-\delta)}+\frac{\delta \alpha_{i} A_{i} M^{\rho-1}}{h_{s}^{2} F_{h_{s}}}\right]+A_{i} \frac{\partial h_{j}}{\partial y},
$$

or in elasticity form,

$$
\begin{aligned}
\frac{\partial h_{j}}{\partial \alpha_{i}} \frac{\alpha_{i}}{h_{i}} & =-\left[\frac{h_{i}}{h_{s}} \frac{1}{(1-\delta)}+\frac{\delta \alpha_{i} A_{i} M^{\rho-1}}{h_{s}^{2} F_{h_{s}}}\right]+\frac{\alpha_{i} A_{i}}{y} \frac{\partial h_{j}}{\partial y} \frac{y}{h_{j}} \\
& =-\left[\frac{1}{(1-\delta)} \frac{P_{i}}{\sum_{l} P_{l}}+\frac{\delta \alpha_{i} A_{i} M^{\rho-1}}{h_{s}^{2} F_{h_{s}}}\right]+\frac{\alpha_{i} A_{i}}{y} \frac{\partial h_{j}}{\partial y} \frac{y}{h_{j}},
\end{aligned}
$$

where the last line uses the fact that $h_{j}=\frac{P_{j}}{\sum_{l} P_{l}} h_{s}$.

\section{Cross-price elasticity, $A_{j}$}

$$
\begin{aligned}
\frac{d A_{j}}{d \alpha_{i}} & =b_{j} h_{j}^{\delta-1} \delta \frac{d h_{j}}{d \alpha_{i}} \\
& =\frac{A_{j}}{h_{j}} \delta \frac{d h_{j}}{d \alpha_{i}}
\end{aligned}
$$

or in elasticity form,

$$
\begin{aligned}
\frac{d A_{j}}{d \alpha_{i}} \frac{\alpha_{i}}{A_{j}} & =\delta \frac{\alpha_{i}}{h_{j}} \frac{d h_{j}}{d \alpha_{i}} \\
\eta_{A_{j}, \alpha_{i}} & =\delta \eta_{h_{j}, \alpha_{i} .}
\end{aligned}
$$




\section{Appendix A2: Composite Services}

To aggregate services we use the hicks composite commodity theorem ${ }^{26}$

Given $n$ services that can be provided by a physician, the vector of service quantities is $\left(A_{1}, A_{2}, \ldots, A_{n}\right)$ and the associated price vector is $\left(\alpha_{1}, \alpha_{2}, \ldots, \alpha_{n}\right)$. Note, for example, if prices $i$ and $j$ move in the same proportion $\theta$ with respect to their base-period prices, denoted $\alpha_{i}^{0}, \alpha_{j}^{0}$, then we can write

$$
\alpha_{i, t}=\theta_{t} \alpha_{i}^{0} \quad \text { and } \quad \alpha_{j, t}=\theta_{t} \alpha_{j}^{0} .
$$

The relative prices of services $i$ and $j$ are constant in each period:

$$
\frac{\alpha_{i t}}{\alpha_{j t}}=\frac{\alpha_{i}^{0}}{\alpha_{j}^{0}} .
$$

Now let $q<n$ be the number groups of services with distinct changes in service prices. Let $\theta_{1}, \theta_{2}, \ldots, \theta_{q}$ denote those price changes and let $\Theta_{j}$ denote the group of services associated with each $\theta_{j}, \quad j \in\{1,2, \ldots, q\}$.

Proposition: If $\left(A_{1}, A_{2}, \ldots, A_{n}\right)$ solves

$$
\begin{aligned}
\max _{\left\{M, h_{1}, h_{2}, \ldots h_{n}, h_{t}, h_{s}\right\}} U & =\left[M^{\rho}+\left(h_{t}-h_{s}\right)^{\rho}+\left(T-h_{t}\right)^{\rho}\right]^{\frac{1}{\rho}} \\
\text { s.t. } \quad \text { (i) } M & =\sum_{j=1}^{n} \alpha_{j} A_{j}+y . \\
\text { (ii) } A_{j} & =b_{j} h_{j}^{\delta} \epsilon, \quad j=1,2, \ldots, n . \\
\text { (iii) } h_{s} & =\sum_{i=1}^{n} h_{j} .
\end{aligned}
$$

then medical services can be aggregated in $q<n$ groups of services. The aggregate service vector is $\left(\sum_{j \in \Theta_{1}} \alpha_{j}^{0} A_{j}, \sum_{j \in \Theta} \alpha_{j}^{0} A_{j}, \ldots, \sum_{j \in \Theta_{q}} \alpha_{j}^{0} A_{j}\right)$ and the associated price vector is $\left(\theta_{1}, \theta_{2}, \ldots, \theta_{q}\right)$.

Proof: The indirect utility function is $V(w, y)=\left[\left(w h_{s}^{\delta} \epsilon+y\right)^{\rho}+2^{1-\rho}\left(T-h_{s}\right)^{\rho}\right]^{\frac{1}{\rho}}$, where $w=$ $\left[\sum_{j=1}^{n}\left(b_{j} \alpha_{j}\right)^{\frac{1}{1-\delta}}\right]^{1-\delta}$. The expenditure function, $e\left(w, u^{0}\right)$, is the amount of non labor income needed to set to $V\left(w, e\left(w, u^{0}\right)\right)=u^{0}$. This gives:

$$
\begin{aligned}
{\left[\left(w h_{s}^{\delta} \epsilon+e\left(w, u^{0}\right)\right)^{\rho}+2^{1-\rho}\left(T-h_{s}\right)^{\rho}\right]^{\frac{1}{\rho}} } & =u^{0} \text { or } \\
e\left(w, u^{0}\right) & =\left[\left(u^{0}\right)^{\rho}-2^{1-\rho}\left(T-h_{s}\right)^{\rho}\right]^{1 / \rho}-w h_{s}^{\delta} \epsilon .
\end{aligned}
$$

\footnotetext{
${ }^{26}$ See, for example, Deaton and Muellbauer (1980).
} 
Applying Shephard's Lemma, the appropriate composite service is the derivative of $e\left(w, u^{0}\right)$ with respect to $\theta_{i}$ (conditional on $h_{s}$ ). We have:

$$
-\frac{d e}{d \theta_{i}}=\frac{d w}{d \theta_{i}} h_{s}^{\delta} \epsilon
$$

The derivative of $w$ with respect to $\theta_{i}$ is

$$
\begin{aligned}
\frac{d w}{d \theta_{i}} & =\frac{d}{d \theta_{i}}\left(\sum_{j \in \Theta_{1}}\left(b_{j} \theta_{1} \alpha_{j}^{0}\right)^{\frac{1}{1-\delta}}+\sum_{j \in \Theta_{2}}\left(b_{j} \theta_{2} \alpha_{j}^{0}\right)^{\frac{1}{1-\delta}}+\ldots+\sum_{j \in \Theta_{i}}\left(b_{j} \theta_{i} \alpha_{j}^{0}\right)^{\frac{1}{1-\delta}}+\ldots+\sum_{j \in \Theta_{q}}\left(b_{j} \theta_{q} \alpha_{j}^{0}\right)^{\frac{1}{1-\delta}}\right)^{1-\delta} \\
& =\sum_{j \in \Theta_{i}} b_{j} \alpha_{j}^{0}\left(\frac{\left(b_{j} \alpha_{j}\right)^{\frac{1}{1-\delta}}}{\Delta}\right)^{\delta},
\end{aligned}
$$

where

$$
\begin{aligned}
\Delta & =\sum_{j \in \Theta_{1}}\left(b_{j} \theta_{1} \alpha_{j}^{0}\right)^{\frac{1}{1-\delta}}+\sum_{j \in \Theta_{2}}\left(b_{j} \theta_{2} \alpha_{j}^{0}\right)^{\frac{1}{1-\delta}}+\ldots+\sum_{j \in \Theta_{i}}\left(b_{j} \theta_{i} \alpha_{j}^{0}\right)^{\frac{1}{1-\delta}}+\ldots+\sum_{j \in \Theta_{q}}\left(b_{j} \theta_{q} \alpha_{j}^{0}\right)^{\frac{1}{1-\delta}} \\
& =\sum_{j \in \Theta_{1}}\left(b_{j} \alpha_{j}\right)^{\frac{1}{1-\delta}}+\sum_{j \in \Theta_{2}}\left(b_{j} \alpha_{j}\right)^{\frac{1}{1-\delta}}+\ldots+\sum_{j \in \Theta_{i}}\left(b_{j} \alpha_{j}\right)^{\frac{1}{1-\delta}}+\ldots+\sum_{j \in \Theta_{q}}\left(b_{j} \alpha_{j}\right)^{\frac{1}{1-\delta}} .
\end{aligned}
$$

Substituting into 47 , we have:

$$
-\frac{d e}{d \theta_{i}}=\sum_{j \in \Theta_{i}} b_{j} \alpha_{j}^{0}\left(\frac{\left(b_{j} \alpha_{j}\right)^{\frac{1}{1-\delta}}}{\Delta}\right)^{\delta} h_{s}^{\delta} \epsilon .
$$

The optimal allocation of hours across services implies

$$
h_{j}=\frac{\left(b_{j} \alpha_{j}\right)^{\frac{1}{1-\delta}}}{\Delta} h_{s} .
$$

Hence,

$$
\begin{aligned}
\frac{d e}{d \theta_{i}} & =\sum_{j \in \Theta_{i}} \alpha_{j}^{0} b_{j} h_{j}^{\delta} \epsilon \\
& =\sum_{j \in \Theta_{i}} \alpha_{j}^{0} A_{j} .
\end{aligned}
$$

The composite service is total revenue generated from the services in $\Theta_{i}$ during period $t$, evaluated at base-period prices. The price of the composite service is $\theta$, the percent change in prices over 
time.

\subsection{Aggregation over services with different $b^{\prime} \mathrm{s}$}

Let $\mathcal{A}_{k}$ denote a group of services $A_{j}, j=\left\{1,2, \ldots, J_{\mathcal{A}_{k}}\right\}$, within which relative prices are constant across services. Then, in any period $t$,

$$
\alpha_{j, t}=\theta_{t} \alpha_{j, 0} \quad\left\{j: A_{j} \in \mathcal{A}_{k}\right\}
$$

from which it follows that:

$$
\alpha_{j, t}=\psi_{j} \alpha_{1_{k}, t} \quad \forall t \quad \text { and } \quad j \in\left\{2, \ldots, J_{\mathcal{A}_{k}}\right\}, \quad \text { where } \quad \psi_{j}=\frac{\alpha_{j, 0}}{\alpha_{1_{k}, 0}}
$$

which is constant over time.

The earnings of physician $k$ in period $t$ are then given by:

$$
\begin{aligned}
\mathcal{E}_{k, t} & =\left[\sum_{k} \sum_{A_{j} \in \mathcal{A}_{k}}\left(\alpha_{j, t} b_{j}\right)^{\frac{1}{1-\delta}}\right]^{1-\delta} h_{s}^{\delta} \epsilon \\
& =\left[\sum_{k} \sum_{A_{j} \in \mathcal{A}_{k}} \alpha_{1_{k}, t}^{\frac{1}{1-\delta}}\left(b_{1}^{\frac{1}{1-\delta}}+\sum_{j=2}^{J} \psi_{j}^{\frac{1}{1-\delta}} b_{j} \frac{1}{1-\delta}\right)\right]^{1-\delta} h_{s}^{\delta} \epsilon_{t} \\
& =\left\{\sum_{k} \sum_{A_{j} \in \mathcal{A}_{k}} \theta_{k, t}^{\frac{1}{1-\delta}}\left[\left(\alpha_{1_{k}, 0} b_{1}\right)^{\frac{1}{1-\delta}}+\sum_{j=2}^{J}\left(\alpha_{1_{k}, 0} \psi_{j} b_{j}\right)^{\frac{1}{1-\delta}}\right]\right\}^{1-\delta} h_{s}^{\delta} \epsilon_{t} \\
& =\left\{\sum_{k} \sum_{A_{j} \in \mathcal{A}_{k}} \theta_{k, t}^{\frac{1}{1-\delta}}\left[\left(\alpha_{1_{k}, 0} b_{1_{k}}\right)^{\frac{1}{1-\delta}}+\sum_{j=2}^{J}\left(\alpha_{j_{k}, 0} b_{j_{k}}\right)^{\frac{1}{1-\delta}}\right]\right\}^{1-\delta} h_{s}^{\delta} \epsilon_{t} \\
= & {\left[\sum_{k} \theta_{k, t}^{\frac{1}{1-\delta}} \tilde{b}_{k}^{\frac{1}{1-\delta}}\right]^{1-\delta} h_{s}^{\delta} \epsilon_{t}, }
\end{aligned}
$$

where $\alpha_{j_{k}, 0}$ denotes the price of the $j^{\text {th }}$ service of group $k$ in the base period 0 . In the presence of heterogenous $b_{j}$ s within the aggregated commodity, we estimate a composite parameter

$$
\tilde{b}_{k}=\sum_{j=2}^{J}\left(\alpha_{j_{k}, 0} b_{j_{k}}\right)^{\frac{1}{1-\delta}},
$$

which is constant over time because the constant $b$ s are weighted by base-level prices through assumption 3 . The aggregate service $k$ is given by the volume of services provided within group $k$, 
weighted at base level prices $\alpha_{j_{k}, 0}$. The price of the aggregate service $\theta_{k, t}$ is the percentage change in prices of the services in group $k$, relative to the base period $t=0$. 


\section{Appendix A3: Data}

The first group of specialists, which we denote $G_{2}$, provided 2 services. It has, in turn, two subgroups. $G_{12}$ is made up of physicians who suppled services 1 and 2. It contains specialities Endocrinology , Otorhinolaryngology, Gastroenterology, and Cardiology. $G_{13}$ is made up of neurologists who supplied services 1 and 3. Earnings for specialist $s$ in $G_{2}$ are calculated as

$$
E_{s}=\alpha_{1} A_{1 s}+\alpha_{2^{\prime}} A_{2^{\prime} s^{\prime}}
$$

where $\alpha_{2^{\prime}}=\mathbb{1}_{G_{12}}(s) \alpha_{2}+\mathbb{1}_{G_{13}}(s) \alpha_{3}$ and $A_{2^{\prime} s}=\mathbb{1}_{G_{12}}(s) A_{2 s}+\mathbb{1}_{G_{13}}(s) A_{3 s}$ with $\mathbb{1}_{G_{i j}}(s)=1$ if the specialist $s$ belongs to the subgroup $G_{i j} ; 0$ otherwise. $A_{j s}$ is the observed quantity of service $j=$ $1,2,3$ provided by specialist $s$ and $\alpha_{j}$ the fee paid for service $j$.

For physicians providing 3 services, we have $G_{3}=G_{123} \cup G_{125} \cup G_{126}$ where $G_{123}, G_{125}, G_{126}$ are 3 disjoint subsets. $G_{123}$ contains physicians who offered services 1, 2 and 3. It is made up of General surgeons and dermatologists .

The subgroup $G_{125}$ contains physicians who provided services 1, 2 and 5. It is made up of pediatricians. $G_{126}$ represents physicians who offered services 1,2 and 6 . It is made up of internal medicine physicians. Earnings for each specialist $s$ in this case is computed as

$$
E_{s}=\alpha_{1} A_{1 s}+\alpha_{2} A_{2 s}+\alpha_{3^{\prime}} A_{3^{\prime} s}
$$

where

$$
\begin{aligned}
\alpha_{3^{\prime}} & =\alpha_{3} \mathbb{1}_{G_{123}}(s)+\alpha_{5} \mathbb{1}_{G_{125}}(s)+\alpha_{6} \mathbb{1}_{G_{126}}(s) \\
A_{3^{\prime} s} & =A_{3} \mathbb{1}_{G_{123}}(s)+A_{5 s} \mathbb{1}_{G_{125}}(s)+A_{6 s} \mathbb{1}_{G_{126}}(s)
\end{aligned}
$$

with $\mathbb{1}_{G_{12 k}}(s)=1$ if $s$ belongs to the subgroup $G_{12 k}(k=3,5,6)$ and 0 otherwise; $A_{j s}$ is the observed quantity of service $j=1,2,3,5,6$ provided by specialist $s$ and $\alpha_{j}$ the fee of service $j$.

The last case we can find in data is the one in which each specialist supplies 4 services. We denote this group of physicians, $G_{4}$. It includes two separate subgroups. $G_{1234}$ contains specialists who provided services 1, 2, 3, and 4. It contains physicians who specialize in Obstetrics and Gynecology. Physicians in the second subgroup $G_{1245}$ provided services 1, 2, 4 and 5 . In this set we find only Orthopedic surgeons. Finally, $G_{4}=G_{1234} \cup G_{1245}$ and $G_{1234} \cap G_{1245}=\varnothing$. We calculate physician's earning for this group as

$$
E_{s}=\alpha_{1} A_{1 s}+\alpha_{2} A_{2 s}+\alpha_{4} A_{4 s}+\alpha_{4^{\prime}} A_{4^{\prime} s^{\prime}}
$$


where

$$
\begin{aligned}
\alpha_{4^{\prime}} & =\alpha_{3} \mathbb{1}_{G_{1234}}(s)+\alpha_{5} \mathbb{1}_{G_{1245}}(s) \\
A_{4^{\prime} s} & =A_{3 s} \mathbb{1}_{G_{1234}}(s)+A_{5 s} \mathbb{1}_{G_{1245}}(s)
\end{aligned}
$$

with $\mathbb{1}_{G_{124 k}}(s)=1$ if $s$ belongs to the subgroup $G_{124 k}(k=3,5)$ and 0 otherwise; $A_{j s}$ is the observed quantity of service $j=1,2,3,4,5$ provided by specialist $s$ and $\alpha_{j}$ the fee of service $j$. 
Table 9: Personal income tax structure in Québec 1996-2002

\begin{tabular}{|c|c|c|c|c|}
\hline Year & Bracket Lower Bound & Federal Rate & Provincial Rate & Combined Rates \\
\hline 1996 & 0 & 0.17 & 0.16 & 0.33 \\
\hline 1996 & 7000 & 0.17 & 0.19 & 0.36 \\
\hline 1996 & 14000 & 0.17 & 0.21 & 0.38 \\
\hline 1996 & 23000 & 0.17 & 0.23 & 0.4 \\
\hline 1996 & 29590 & 0.26 & 0.23 & 0.49 \\
\hline 1996 & 50000 & 0.26 & 0.24 & 0.5 \\
\hline 1996 & 59180 & 0.29 & 0.24 & 0.53 \\
\hline 1997 & 0 & 0.17 & 0.16 & 0.33 \\
\hline 1997 & 7000 & 0.17 & 0.19 & 0.36 \\
\hline 1997 & 14000 & 0.17 & 0.21 & 0.38 \\
\hline 1997 & 23000 & 0.17 & 0.23 & 0.4 \\
\hline 1997 & 29590 & 0.26 & 0.23 & 0.49 \\
\hline 1997 & 50000 & 0.26 & 0.24 & 0.5 \\
\hline 1997 & 59180 & 0.29 & 0.24 & 0.53 \\
\hline 1998 & 0 & 0.17 & 0.2 & 0.37 \\
\hline 1998 & 25000 & 0.17 & 0.23 & 0.4 \\
\hline 1998 & 29590 & 0.26 & 0.23 & 0.49 \\
\hline 1998 & 50000 & 0.26 & 0.26 & 0.52 \\
\hline 1998 & 59180 & 0.29 & 0.26 & 0.55 \\
\hline 1999 & 0 & 0.17 & 0.2 & 0.37 \\
\hline 1999 & 25000 & 0.17 & 0.23 & 0.4 \\
\hline 1999 & 29590 & 0.26 & 0.23 & 0.49 \\
\hline 1999 & 50000 & 0.26 & 0.26 & 0.52 \\
\hline 1999 & 59180 & 0.29 & 0.26 & 0.55 \\
\hline 2000 & 0 & 0.17 & 0.19 & 0.36 \\
\hline 2000 & 26000 & 0.17 & 0.225 & 0.395 \\
\hline 2000 & 30004 & 0.25 & 0.225 & 0.475 \\
\hline 2000 & 52000 & 0.25 & 0.25 & 0.5 \\
\hline 2000 & 60009 & 0.29 & 0.25 & 0.54 \\
\hline 2001 & 0 & 0.16 & 0.17 & 0.33 \\
\hline 2001 & 26000 & 0.16 & 0.2125 & 0.3725 \\
\hline 2001 & 30754 & 0.22 & 0.2125 & 0.4325 \\
\hline 2001 & 52000 & 0.22 & 0.245 & 0.465 \\
\hline 2001 & 61509 & 0.26 & 0.245 & 0.505 \\
\hline 2001 & 100000 & 0.29 & 0.245 & 0.535 \\
\hline 2002 & 0 & 0.16 & 0.16 & 0.32 \\
\hline 2002 & 26700 & 0.16 & 0.2 & 0.36 \\
\hline 2002 & 31677 & 0.22 & 0.2 & 0.42 \\
\hline 2002 & 53405 & 0.22 & 0.24 & 0.46 \\
\hline 2002 & 63354 & 0.26 & 0.24 & 0.5 \\
\hline 2002 & 103000 & 0.29 & 0.24 & 0.53 \\
\hline
\end{tabular}

Source: Milligan (2016) 